NBER WORKING PAPER SERIES

HEALTH CAPACITY TO WORK AT OLDER AGES IN DENMARK

\author{
Paul Bingley \\ Nabanita Datta Gupta \\ Peder Pedersen \\ Working Paper 22018 \\ http://www.nber.org/papers/w22018 \\ NATIONAL BUREAU OF ECONOMIC RESEARCH \\ 1050 Massachusetts Avenue \\ Cambridge, MA 02138 \\ February 2016
}

This paper is part of the National Bureau of Economic Research's International Social Security (ISS) Project, which is supported by the National Institute on Aging (grant P01 AG012810). We are grateful to other ISS project team members for comments which have improved the paper. This paper uses data from SHARE wave 5 release 1.0.0, as of March 31st 2015 (DOI: 10.6103/SHARE.w5.100), SHARE wave 4 release 1.1.1, as of March 28th 2013 (DOI: 10.6103/SHARE.w4.111), SHARE waves 1 and 2 release 2.6.0, as of November 29th 2013 (DOIs: 10.6103/SHARE.w1.260 and 10.6103/SHARE.w2.260). The SHARE data collection has been primarily funded by the European Commission through the 5th Framework Program (project QLK6-CT- 2001-00360 in the thematic program Quality of Life), through the 6th Framework Program (projects SHARE-I3, RII-CT-2006-062193, COMPARE, CIT5-CT-2005-028857, CIT4-CT-2006-028812) and through the 7th Framework Program (SHARE-PREP, N ${ }^{\circ}$ 211909, SHARE-LEAP, N ${ }^{\circ} 227822$ and SHARE M4, $\mathrm{N}^{\circ}$ 261982). Additional funding from the U.S. National Institute on Aging (U01 AG09740-13S2, P01 AG005842, P01 AG08291, P30 AG12815, R21 AG025169, Y1AG-4553-01, IAG BSR06-11 and OGHA 04-064) and the German Ministry of Education and Research as well as from various national sources is gratefully acknowledged (see www.shareproject.org for a full list of funding institutions). The views expressed herein are those of the authors and do not necessarily reflect the views of the National Bureau of Economic Research.

NBER working papers are circulated for discussion and comment purposes. They have not been peer-reviewed or been subject to the review by the NBER Board of Directors that accompanies official NBER publications.

(C) 2016 by Paul Bingley, Nabanita Datta Gupta, and Peder Pedersen. All rights reserved. Short sections of text, not to exceed two paragraphs, may be quoted without explicit permission provided that full credit, including $\odot$ notice, is given to the source. 
Health Capacity to Work at Older Ages in Denmark

Paul Bingley, Nabanita Datta Gupta, and Peder Pedersen

NBER Working Paper No. 22018

February 2016

JEL No. I14,J26

\begin{abstract}
$\underline{\text { ABSTRACT }}$
Longevity is increasing and many people are spending a greater proportion of their lives reliant on pensions to support consumption. In response to this, several countries have mandated delays to age of first entitlement to pension benefits in order to reduce incentives to retire early. However, it is unknown to what extent older individuals have the health capacity to sustain the longer working lives that delayed pension benefits may encourage. We estimate the health capacity to work longer in Denmark by comparing how much older individuals work today with how much those with similar mortality rates worked in the past, and how much younger individuals today with similar self-assessed health work. We find substantial health capacity for longer working lives among those currently aged 55 and above. We also find significant heterogeneity by education and gender. Those with a high school degree have the greatest additional work capacity, women have more additional capacity than men, especially women with a college degree.

\author{
Paul Bingley \\ SFI-The Danish National Centre \\ for Social Research \\ Herluf Trolles Gade 11 \\ 1052 Copenhagen $\mathrm{K}$ \\ Denmark \\ pab@sfi.dk \\ Nabanita Datta Gupta \\ Department of Economics and \\ Business Economics \\ Aarhus University \\ Fuglesangs Allé 4 \\ 8210 Aarhus V \\ Denmark \\ ndg@econ.au.dk
}

\author{
Peder Pedersen \\ Department of Economics and \\ Business Economics \\ Aarhus University \\ Fuglesangs Allé 4 \\ 8210 Aarhus V \\ Denmark \\ ppedersen@econ.au.dk
}




\section{Health capacity to work at older ages in Denmark}

\section{Introduction}

Many countries are increasing the ages at which pension benefits are first available, and thereby reducing incentives to retire early. Moreover, with increased life expectancy, the global move from defined benefit towards defined contribution pension plans implies lower per period consumption, all else equal, unless individuals work longer and retire later. Both of these changes push toward delayed retirement, but it remains to be shown that individuals have the health capacity to sustain extended working lives. Indeed, much of the work we have done in previous stages of the International Social Security project (Wise, 2015), which relates to retirement age responsiveness to pension incentives (Bingley, et.al., 2004), health (Bingley, et.al., 2012) and disability insurance (Bingley, et.al., 2015), implicitly assumes that individuals have sufficient unused health capacity to work at older ages. In this study we will estimate how much unused health capacity to work exists.

Amongst OECD countries, Denmark has relatively short life expectancy and late age of first eligibility to old age pension. These combined to give Danes the lowest life expectancy after pensionable age 1993-2002 (13.4 years for men and 16.6 years for women). Old age pension benefits could first be received at age 67 until 2004, and this was reduced to age 65 by 2006 in 6 month steps. In 2011 it was announced that during 2019-22 the age of first eligibility will once again be raised to 67 in 6 month steps. Life expectancy after pensionable age jumped by 3 years during the 2000 decade, the largest increase of all countries, but after the 2019-22 reform is implemented Danes will once again have the shortest expected retirements (OECD 2011).

Denmark was the first country to automatically link pensions to life expectancy in their retirement income system (Whitehouse, 2007). From 2030, Denmark will link changes in age of first eligibility to old age pension to changes in life expectancy from age 60. The aim is to maintain life expectancy after pensionable age close to the 14.5 years observed in 2004-5, the two years before the automatic linkage reform was announced (Ministry of Integration and Social Affairs, 2013). However, the rate of increase due to automatic linkage with life expectancy is capped such that pensionable age can at most increase by one year every fifth year. Projected life expectancy from age 60 in 2025 (minus 14.5 years) is rounded to the nearest half year to give the implied pensionable age in 2030. The projection to 2025 uses life expectancy from age 60 during 2013-14 and assumes a trend which 
adds 0.6 years. These calculations imply a pensionable age in 2030 of 69.5 years, but since pensionable age can only increase by at most one year, eligibility will be from age 68 in 2030 .

In several countries, gains in longevity are expected to outpace announced future delays in pensionable ages. Denmark has amongst the shortest life expectancies after pensionable age and has a history of policy attention to the measure. This makes Denmark an excellent case for measuring health capacity for extending the working life, since post retirement longevity itself, regardless of health status, is a greater constraint in Denmark than anywhere else. Finding unused work capacity in Denmark ought to be a greater challenge because of the high base of work capacity used already.

In this paper we ask to what extent older Danes have the health capacity to extend their working lives. We do this by estimating health-employment relationships in the past, or for younger cohorts today, and predicting how much work capacity there would be for older cohorts in similar health today if those estimated relationships held for today's older cohorts. Ideally we would like to know what the health-employment relationship might be in the absence of non-health-related social security programs. We take two approaches to obtaining this counterfactual health-employment relationship, by fitting the relationship historically before the introduction of early pension benefit programs, or by fitting the relationship for younger cohorts today who have not yet reached pension benefit eligibility age.

For the first approach following Milligan and Wise (2012), we look at the historical relationship between mortality and employment rates and ask how much would older people work today, given current mortality rates, if they were to work as much as they did at a similar mortality rate in the past? Using published data from Statistics Denmark, we plot the mortality-employment relationship for several years from 1977 to 2010 and find significant unused work capacity compared to today for all baselines up until 2000. We only estimate mortality-employment relations for men for the sake of better comparison with other countries, where increasing older female labor market participation makes estimates for women difficult to interpret.

For the second approach, inspired by Cutler and coauthors (2012), we estimate the relationship between self-assessed health (SAH) and employment for somewhat younger cohorts and ask how much older cohorts, with similar SAH, would work if the same health-employment relationship 
held. We use micro data from the Survey of Health and Retirement in Europe for Denmark (SHARE-Denmark) collected 2004-13 to estimate the relationship for those aged 50-54 and to predict work capacity for ages 55-74. We find significant unused work capacity from age 60 and older for both men and women. Estimated unused work capacity is remarkably similar for the group that we consider using both methods - for men aged 55-69 - when we use a 1977 mortalityemployment relationship baseline. The Cutler method implies 4.8 years and the Milligan-Wise method implies 4.6 years unused work capacity, compared to 7.6 years currently working. Women are predicted to have slightly more unused work capacity than men using the Cutler method for ages 55-69 at 5.1, compared to 6.1 years currently working.

The remainder of the paper is organized as follows: As background, the next section describes trends in labor force participation, health and mortality. In section 3 we estimate work capacity using the historical mortality-employment relationship following Milligan and Wise (2012). In section 4 we describe trends in SAH and in section 5 we estimate the SAH-employment relationship for younger cohorts following Cutler and coauthors (2012). Finally we conclude with a discussion of the implications of our findings.

\section{Trends in Labor Force Participation and Health}

This section summarizes the trends in labor force participation in Denmark over the last 50 years for men and women aged 60-69. We split the discussion for those aged 60-64 and 65-69 because of data availability and differences in eligibility to pension benefits between these two age groups. Figure 1 presents the evolution of labor force participation for 60-64 year olds based on several different sources. 
Figure 1. Labor Force Participation Rates for ages $60-64$ by gender over time

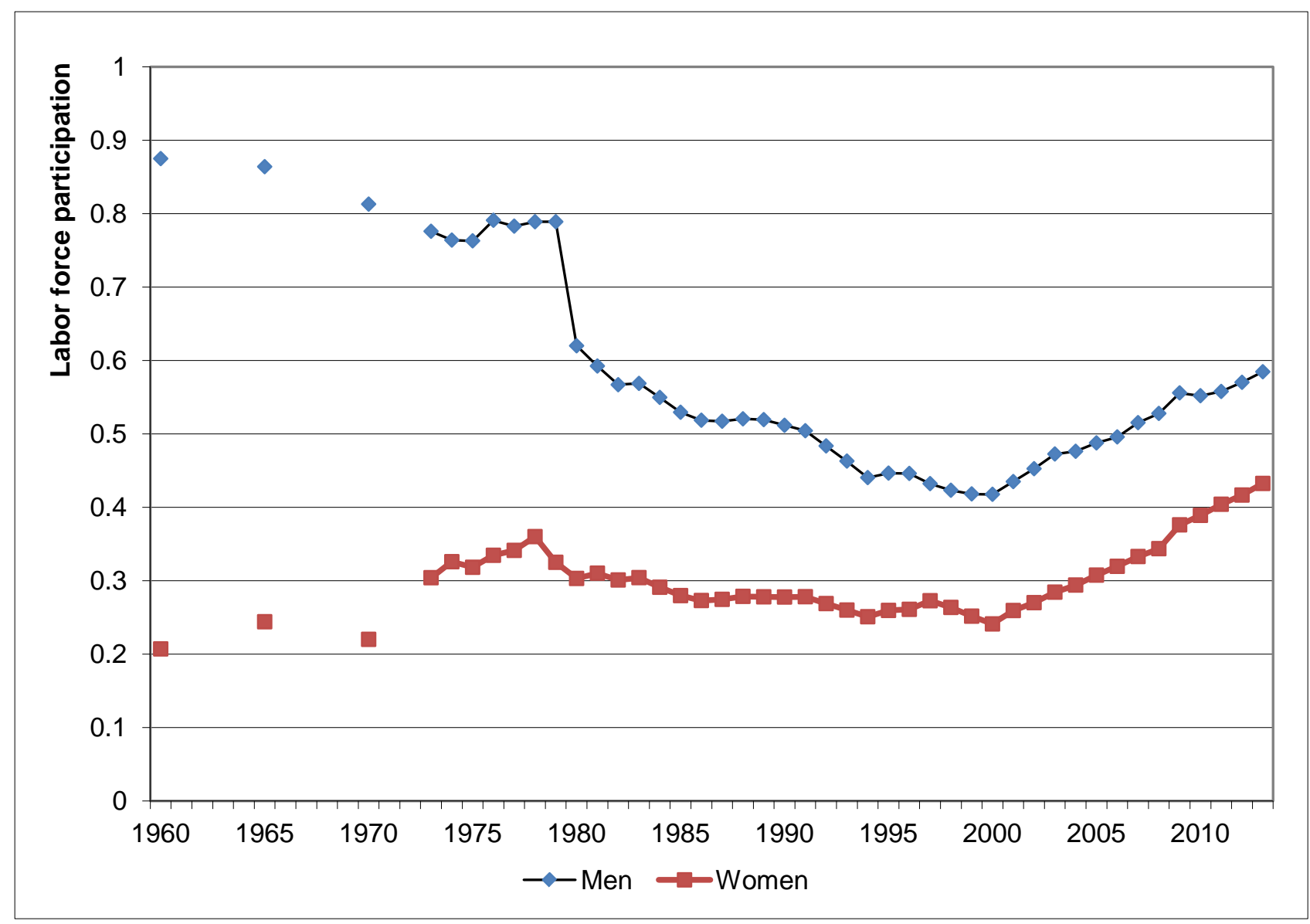

Until the late 1990s, trends in labor force participation by gender are very different from each other, with a 70 percentage point differential in 1960 declining to 18 percentage points by 2013 . The initial decline for men in the 1960s reflects structural change with a sectoral shift of employment from agriculture, which was comprised largely of independent farmers, towards industry. The dramatic decline in labor force participation for men in 1980 is the initial impact from introduction of a non-health related pension benefit program - the Post Employment Wage (PEW - efterløn), with eligibility ages 60-66, depending on sufficiently long membership of an Unemployment Insurance fund. For women, the initial impact was much smaller because of lower baseline participation and less PEW eligibility among working women due to insufficient history of Unemployment Insurance fund membership.

The strong upswing in labor force participation rates from the late 1990s, also found in many other OECD countries, see e.g. Larsen and Pedersen (2013), is the result of several interacting factors. 
Since 1999 a number of policy changes have been made with the aim of discouraging early retirement. Further, average education and health has improved strongly for this group with retirement age having a positive gradient in both factors, cf. Larsen and Pedersen (2015). Actually, 60-64 year olds are the only age group to have experienced an increase in labor force participation rate since the onset of the Great Recession in 2008. For all younger age groups, participation rates have fallen since 2008, especially among the young. However, in spite of improvements in health to which we return below, labor force participation for men aged 60-64 is still 20 percentage points below the level of the late 1970s. Our aim is to estimate the potential work capacity of today's older cohorts in view of reductions in mortality and SAH improvements of recent years.

In Figure 2 we present the development of labor force participation for those aged 65-69. For men, the initial level is about 30 percentage points lower than for the 60-64 year olds. We find the same steep decline in labor force participation in the second half of the 1960s as found for the 60-64 year olds, reflecting the same switch from independent farming. Following the introduction of PEW in 1979 labor force participation falls, although less steeply than for the 60-64 year olds because, of this older group, only those aged 65-66 were eligible for PEW. The next visible change in labor force participation rates occurs in the years immediately after 2000 which continues the increases in labor force participation for 60-64 year olds in the preceding period. During 2004-2006 65-66 year olds were no longer eligible for PEW as the age for first eligibility to Old Age Pension (folkepension) was reduced from 67 to 65 . The modest upward trends since 2000 is somewhat diminished for men, reflecting this 2004-6 reform. Nevertheless, labor force participation for men in 2013 was half that of 1960 . For women aged 65-69 we see a very small increase in labor force participation after 2000. Overall, however, the level for women is stationary around 10-12 per cent ever since 1960. 
Figure 2. Labor Force Participation Rates for ages 65-69 by gender over time

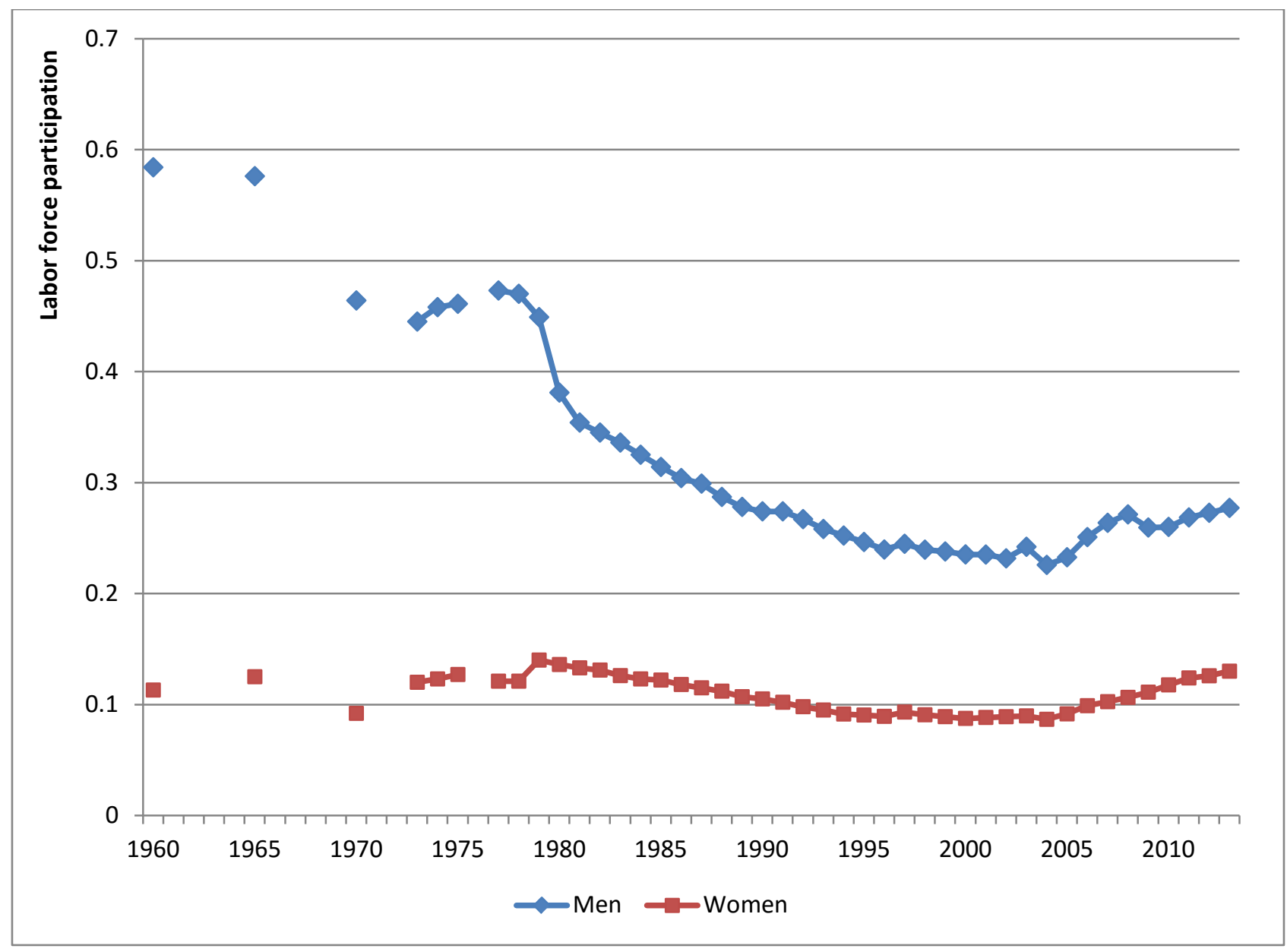

Summing up, for 60-69 year old men labor force participation over the last 30-35 years has declined by about 20 percentage points. As longevity has increased along with level of education, there is clearly scope for analyzing the health related factors behind the potential for reversing this decline as part of accommodating demographic changes in the coming decades.

As an introduction to the analyses of health factors, Figure 3 collects evidence on the development in mortality and self-assessed health for men aged 50-75 over the last 20 years. Data on self assessed health are available also for other years, but 1994 and 2013 are the most recent years where the same questions and response categories were used. The decrease in mortality is strong, despite the period being fairly short, in contrast to the years before the mid-1990s where mortality in Denmark was quite stationary at the same time as mortality was decreasing in most comparable 
countries. The share of men with self-assessed health in the fair-poor categories is lower in 2013 than in 1994 and the gradient with respect to age is more flat in the most recent year.

Figure 3. Male Self-Assessed Health and Mortality by year over age

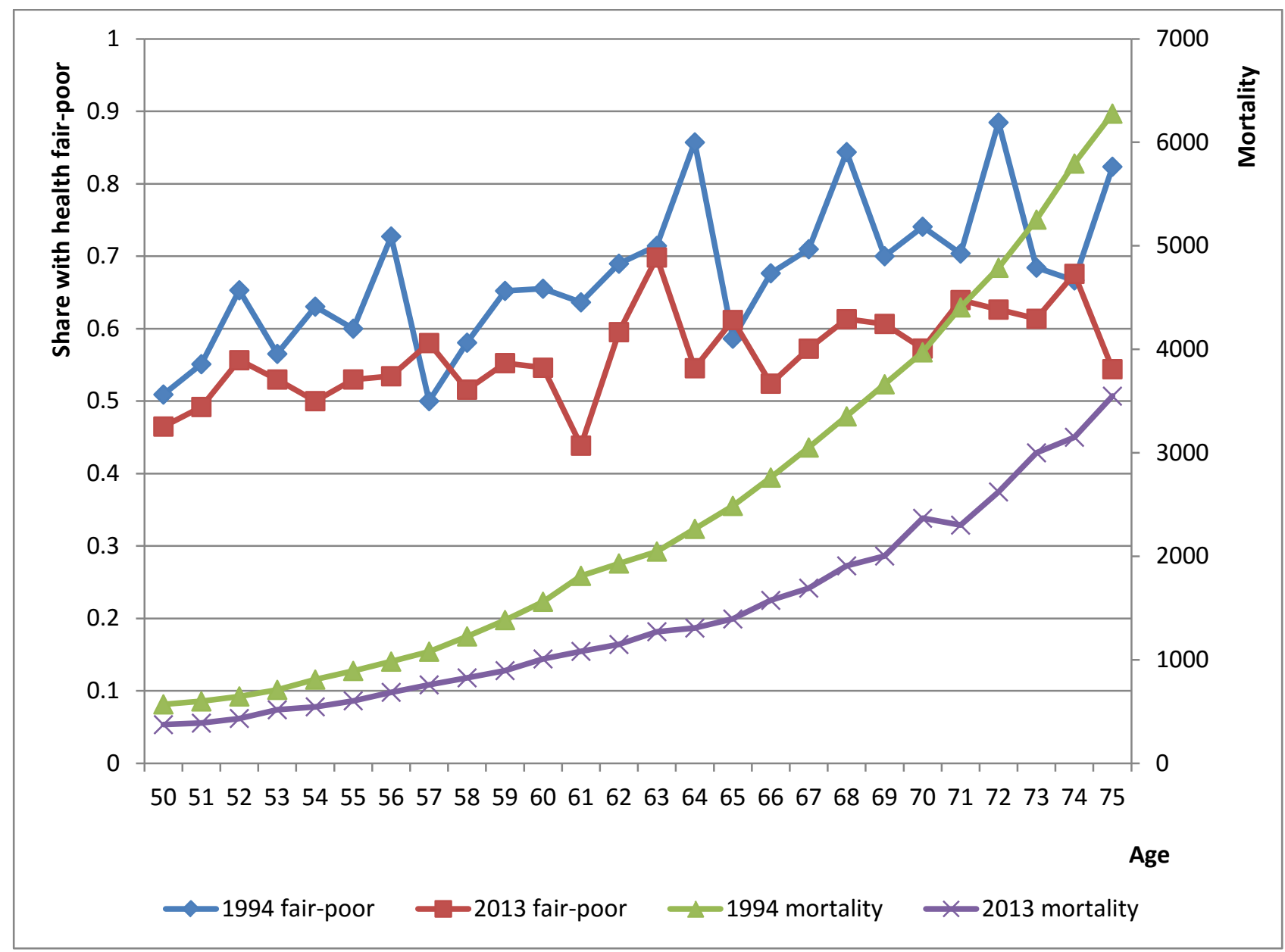

\section{Work Capacity estimates based on historical mortality}

We will use two different methods to assess the health related capacity to work at older ages. The Cutler method is used in Section 5. In this section we present results from applying the methods in Milligan and Wise (2012) to Danish data. The idea is to look at the relationship between mortality and employment at given ages in some earlier year. Next, we look at the employment mortality relationship in a current year. Comparing employment at given levels of mortality in the year back in time and the current year gives an upper-bound estimate of potential extra work capacity in the current year. 
A number of conditions and reservations should be emphasized. First, it is assumed that mortality captures all health factors related to work capacity. One can argue that better measures than mortality could summarize physical and mental capacity for continued work at older ages. However, mortality has the clear advantage of being available over a very long period and being comparable between countries.

Figure 4 plots the relationship between mortality and employment rate for men 55-69 years old in 1977 and 2010.

Figure 4. Male Employment and Mortality by age in 1977 and 2010

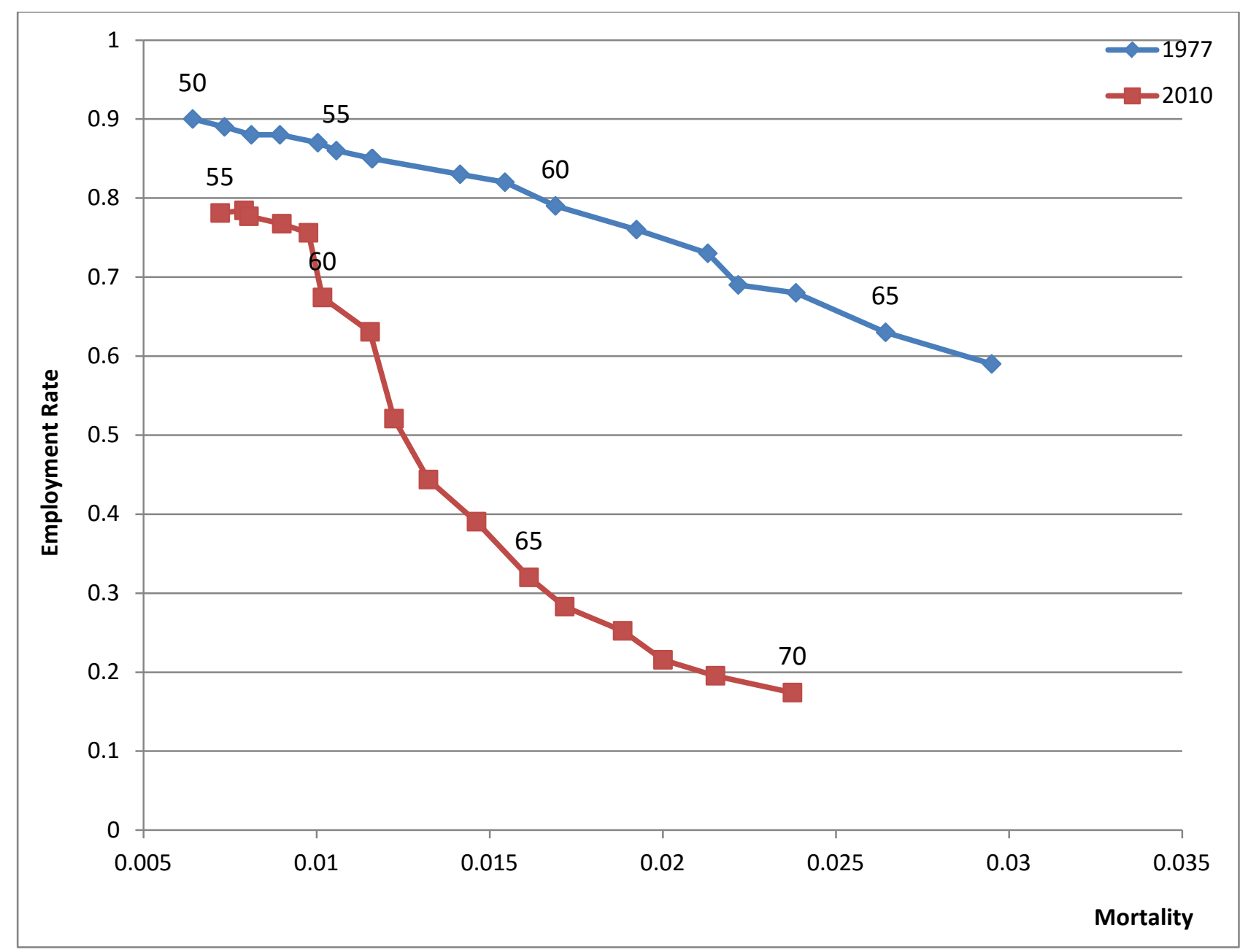

The procedure for calculating the upper bound of the additional capacity for work is based on the lines in Figure 4. For each age, 55-69 years, in 2010 mortality and employment rates are plotted in Figure 4. For instance, at age 60 in 2010 mortality was 1.0 percent and the employment rate was 
67.4 percent. At that level of mortality, the employment rate in 1977 was 86 per cent. Consequently, the upper bound of the additional work capacity in 2010 with 1977 as base year was 18.6 percent. Running this procedure over all ages we find, not surprisingly comparing with Figure 1, that additional work capacity has a steep gradient in age for people in the first half of their 60s.

The results from the exercise are presented in Table 1. In 2010, the total number of working years for men 55-69 years old was 7.8. As a counterfactual, this would correspond to a situation where men 55-63 years old had employment rates of 100 per cent and all retired when reaching age 64. The accumulated additional employment capacity in 2010 with 1977 as base year is 4.7 years, i.e. a sizeable 60 per cent of the actual number of years worked.

Table 1. Additional Male Work Capacity in 2010 Using 1977 Employment-Mortality Relationship.

\begin{tabular}{|c|c|c|c|c|}
\hline Age & Mortality in 2010 & $\begin{array}{c}\text { Employment Rate } \\
\text { in } 2010\end{array}$ & $\begin{array}{c}\text { Employment rate } \\
\text { in } 1977 \text { at same } \\
\text { mortality }\end{array}$ & $\begin{array}{c}\text { Additional Work } \\
\text { Capacity }\end{array}$ \\
\hline 55 & $0.72 \%$ & $78.1 \%$ & $89 \%$ & $10.9 \%$ \\
\hline 56 & $0.79 \%$ & $78.4 \%$ & $88 \%$ & $9.6 \%$ \\
\hline 57 & $0.80 \%$ & $77.7 \%$ & $88 \%$ & $10.3 \%$ \\
\hline 58 & $0.90 \%$ & $76.7 \%$ & $88 \%$ & $11.3 \%$ \\
\hline 59 & $0.98 \%$ & $75.6 \%$ & $87 \%$ & $11.4 \%$ \\
\hline 60 & $1.02 \%$ & $67.4 \%$ & $86 \%$ & $18.6 \%$ \\
\hline 61 & $1.15 \%$ & $63.1 \%$ & $85 \%$ & $21.9 \%$ \\
\hline 62 & $1.22 \%$ & $52.1 \%$ & $85 \%$ & $32.9 \%$ \\
\hline 63 & $1.32 \%$ & $44.4 \%$ & $84 \%$ & $39.6 \%$ \\
\hline 64 & $1.46 \%$ & $39.0 \%$ & $83 \%$ & $44.0 \%$ \\
\hline 65 & $1.61 \%$ & $32.0 \%$ & $80 \%$ & $48.0 \%$ \\
\hline 66 & $1.72 \%$ & $28.3 \%$ & $79 \%$ & $50.7 \%$ \\
\hline 67 & $1.88 \%$ & $25.2 \%$ & $77 \%$ & $51.8 \%$ \\
\hline 68 & $2.00 \%$ & $21.6 \%$ & $75 \%$ & $53.4 \%$ \\
\hline 69 & $2.15 \%$ & $19.5 \%$ & $72 \%$ & $52.5 \%$ \\
\hline Total years & & 7.8 & & 4.7 \\
\hline
\end{tabular}


In Figure 5 the same analysis is made comparing 2010 with the much closer year 1995. While 1977 was two years before the introduction of the PEW program resulting in a steep decline in male employment rates from age 60, 1995 was a low point in employment rates, cf. Figure 1. An obvious consequence is that the two graphs in Figure 5 are much closer to each other than the corresponding curves in Figure 4.

Table 2 summarizes in the same way as Table 1 employment rates and mortality at each age in 2010 along with the employment rate in 1995 at the same mortality rates. A main difference compared with the case using 1977 as base year is the lack of additional employment capacity at ages 55-59. At mortality rates above age 60 level in 2010, we find additional employment capacity, most pronounced at ages 62 to 66 . Overall, the additional employment capacity adds up to 1.6 years, or about one third of the additional employment capacity found in Table 1, which uses a 1977 baseline.

Figure 5. Male Employment and Mortality by age in 1995 and 2010

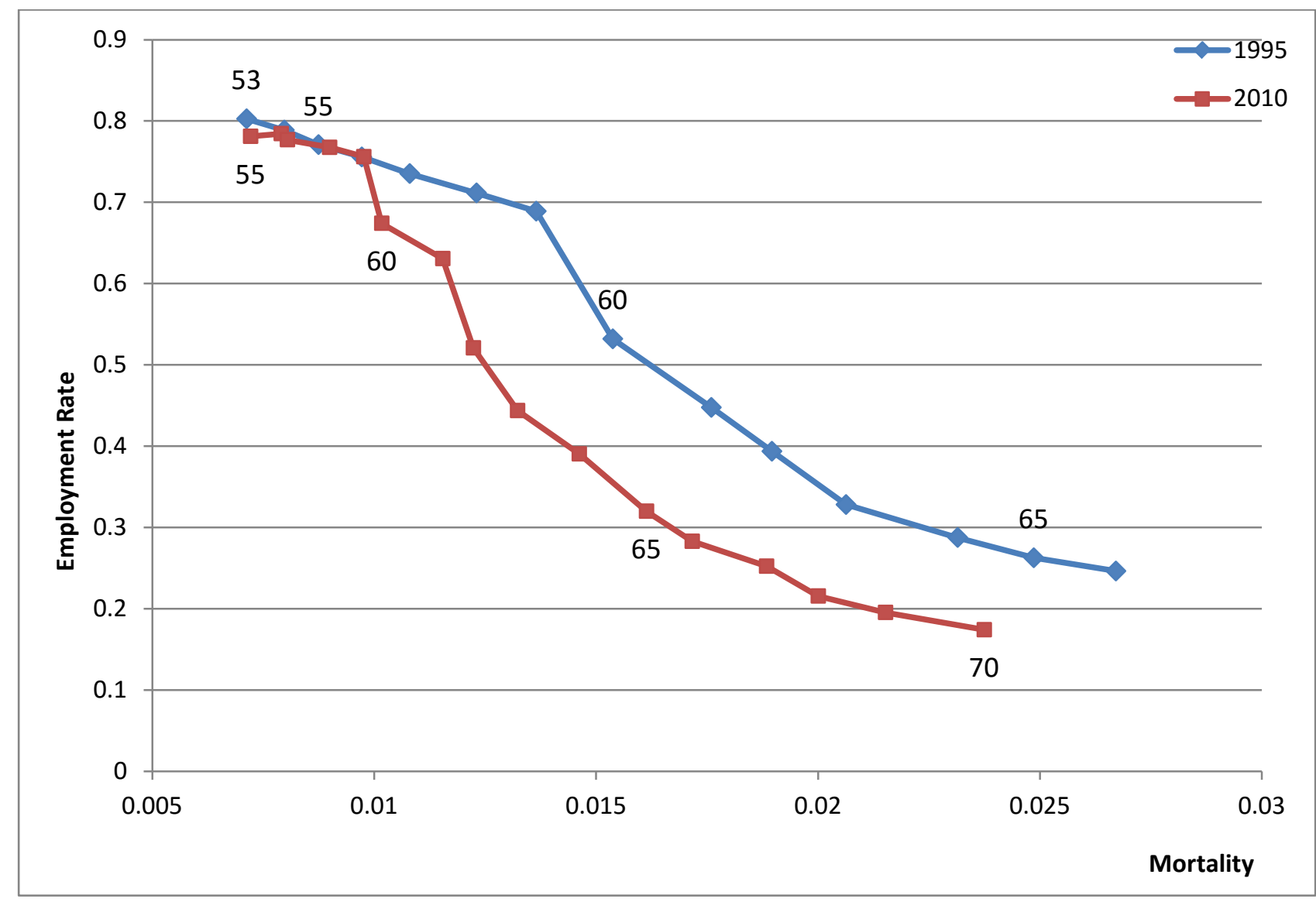


Table 2. Additional Male Work Capacity in 2010 Using 1995 Employment-Mortality Relationship.

\begin{tabular}{|c|c|c|c|c|}
\hline Age & Mortality in 2010 & $\begin{array}{c}\text { Employment Rate } \\
\text { in } 2010\end{array}$ & $\begin{array}{c}\text { Employment rate } \\
\text { in 1995 at same } \\
\text { mortality }\end{array}$ & $\begin{array}{c}\text { Additional Work } \\
\text { Capacity }\end{array}$ \\
\hline 55 & $0.72 \%$ & $78.1 \%$ & $79.0 \%$ & $0.9 \%$ \\
\hline 56 & $0.79 \%$ & $78.4 \%$ & $78.9 \%$ & $0.5 \%$ \\
\hline 57 & $0.80 \%$ & $77.7 \%$ & $78.9 \%$ & $1.2 \%$ \\
\hline 58 & $0.90 \%$ & $76.7 \%$ & $76.7 \%$ & $0.0 \%$ \\
\hline 59 & $0.98 \%$ & $75.6 \%$ & $75.0 \%$ & $-0.6 \%$ \\
\hline 60 & $1.02 \%$ & $67.4 \%$ & $74.6 \%$ & $7.2 \%$ \\
\hline 61 & $1.15 \%$ & $63.1 \%$ & $72.4 \%$ & $9.3 \%$ \\
\hline 62 & $1.22 \%$ & $52.1 \%$ & $71.1 \%$ & $19.0 \%$ \\
\hline 63 & $1.32 \%$ & $44.4 \%$ & $69.7 \%$ & $25.3 \%$ \\
\hline 64 & $1.46 \%$ & $39.0 \%$ & $60.3 \%$ & $21.3 \%$ \\
\hline 65 & $1.61 \%$ & $32.0 \%$ & $50.4 \%$ & $18.4 \%$ \\
\hline 66 & $1.72 \%$ & $28.3 \%$ & $46.3 \%$ & $18.0 \%$ \\
\hline 67 & $1.88 \%$ & $25.2 \%$ & $40.0 \%$ & $14.8 \%$ \\
\hline 68 & $2.00 \%$ & $21.6 \%$ & $35.3 \%$ & $13.7 \%$ \\
\hline 69 & $2.15 \%$ & $19.5 \%$ & $31.4 \%$ & $1.9 \%$ \\
\hline Total years & & 7.8 & & \\
\hline & & & & \\
\hline & & & & \\
\hline
\end{tabular}

Figure 6 is a summary of the trends in the development of the relationship between mortality and employment rates by including average values for three five-year intervals, last half of the 1970s before the PEW program - first half of the 1990s when employment rates reached a minimum and the second half of the 2000 decade. A clear illustration of the change over the period is found looking at the pivotal age of 60. From the late 1970s to the early 1990s the employment rate drops by 20 percentage points with only a slight decline in mortality. Next, from the early 1990s to the late 2000s, employment goes up at age 60 along with declining mortality. From Figure 5 we know, however, that employment for given levels of mortality is still lower in the late 2000s compared with the early 1990s at age 60 and above. 
Figure 6. Male Employment and Mortality 1976-80, 1991-95 and 2006-10.

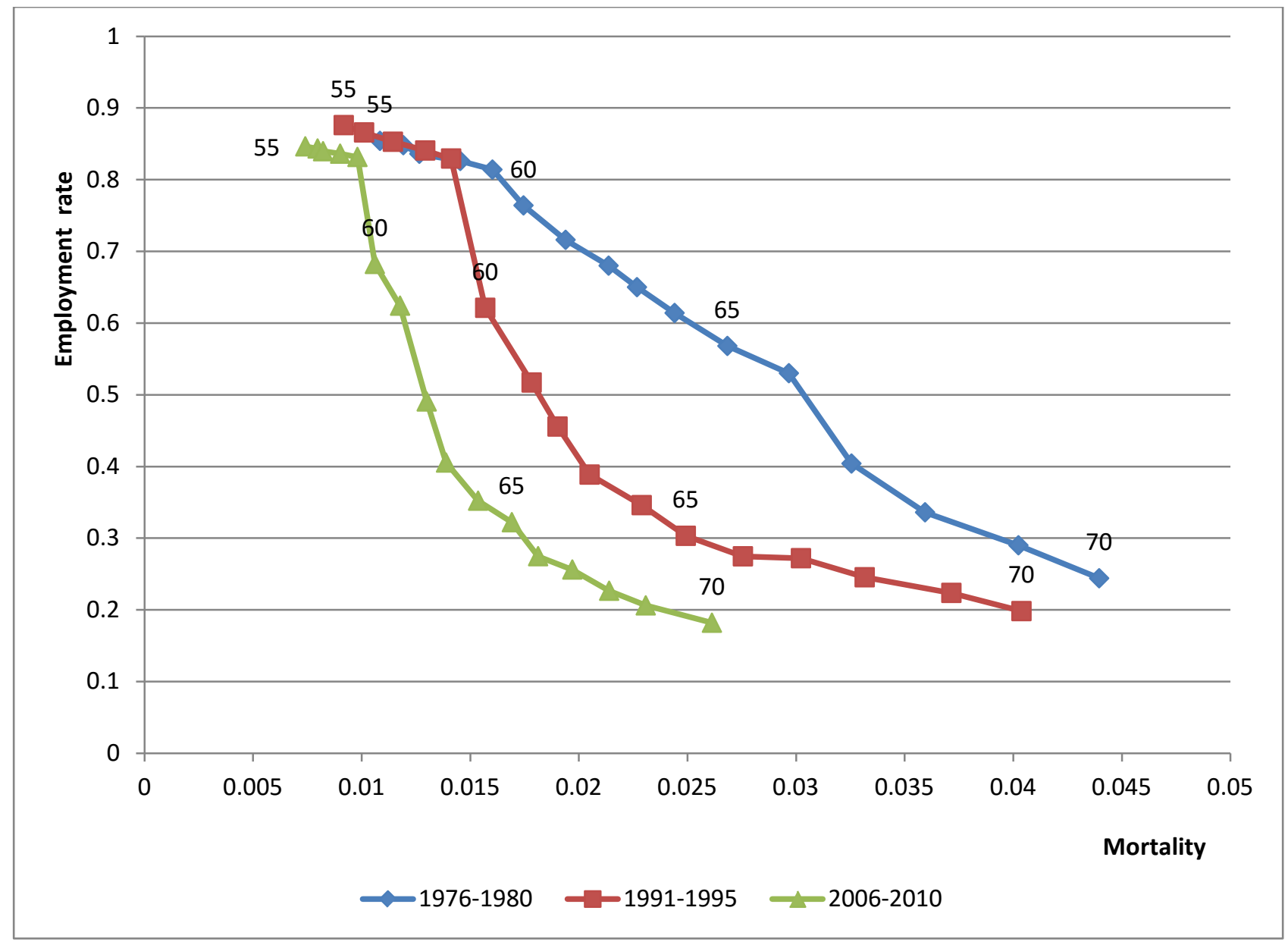

Next, in Figure 7 we have used all the years between 1977 and 2009 as base years comparing with the mortality employment relationship in 2010. As expected the estimated additional work capacity becomes smaller as we move closer to 2010, i.e. differences in mortality rates become smaller and changes in employment rates also become smaller. From about the turn of the century, additional work capacity becomes stationary at a level close to zero as mortality declines faster at the same time as employment rates increase, cf. Figures 1 and 2. 
Figure 7. Additional Male Work Capacity in 2010 by base year for comparison

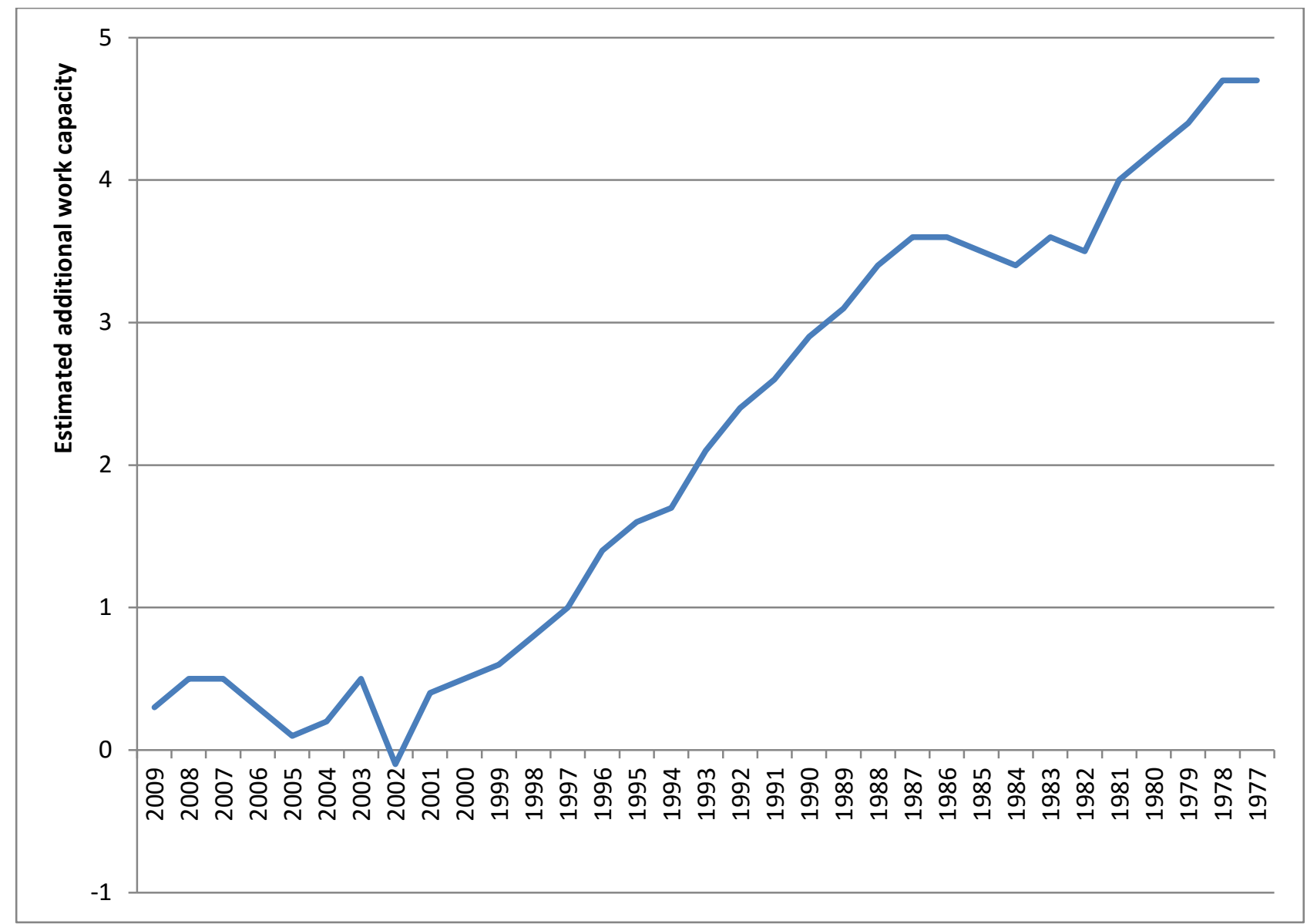

The additional work capacity found by using the Milligan-Wise method does not imply the normative conclusion that older people should continue working in accordance with the increase in employment capacity we find. Our finding should instead be seen as a contribution to the arguments and analyses in the so called "healthy life debate", i.e. to what extent does increasing longevity result in more healthy years with a potential for a longer working life, or is most of the gain spent in poor health and disability. There is a wide ranging literature on this topic of which only a few contributions are mentioned here. Mathers et al. (2001) calculate healthy life expectancy for 191 countries in 1999 using the method of Sullivan (1971) which combines surveys of SAH with life tables. They find that healthy life expectancy increases across countries at a faster rate than total life expectancy. Christensen et al. (2009) present as a conditional projection that most children born in Denmark since the turn of the century will survive until age 100 and older, but it remains to be established whether age of onset of functional limitations and disability increases in a similar way. 
Using Danish data for the year 2000, Brønnum-Hansen et al. (2004) considers life expectancy and health expectancy by educational levels. They find a social gradient in both but the gradient in health expectancy is greater than in life expectancy. Being a cross-section study, it contains only an implicit contribution to answer the question about the development over time. An attempt at an explicit answer is found in Brønnum-Hansen (2005) building on comprehensive Danish surveys 1987-2000, combined with life table data using the Sullivan (1971) method. Over the period, Brønnum-Hansen (2005) finds disability-free life time increasing more than total life expectancy, and more so for men than for women.

\section{Self-Assessed Health and employment by age over time}

An alternative to use of mortality as an overall health indicator is to rely on individuals' own evaluation and study SAH from surveys as an indicator for health related capacity for work. Denmark does not have a time long series of comparable SAH measures. The National Institute of Public Health conducted a number of surveys beginning in 1987. We have access to micro data from the 1987 survey, cf. below. For other years data are available in a processed form and results regarding SAH from two comparable surveys in 1994 and 2013 were included in Figure 3 above. Besides the National Institute of Public Health surveys, we can use the European Community Household Panel (ECHP), SHARE and other smaller surveys. For the purpose of the present study, there are issues regarding lacks of comparability between surveys, coverage of only a short span of time consistently within surveys, and small sample sizes.

Below we present SAH from these surveys and relate this to the age of eligibility to the major social security programs. First, Figure 8 presents the relationship between labor force participation rates and SAH based on a fairly small survey collected in 1977. This provides the only self-assessed health measure before the introduction of PEW. Results from the survey are described and discussed in Olsen (1977). SAH is measured on the horizontal axis as the share reporting their health as fair for my age group to poor. The vertical axis measures average labor force participation rate at each age. In 1977 Disability Insurance (DI) was the only early exit route from the labor market before eligibility for old age pension at age 67. The expected negative slope is found in Figure 8 and the impact of reaching eligibility for old age pension is seen as a decline in labor force 
participation of about 30 percentage points without any visible deterioration of $\mathrm{SAH}$ - if anything health improves for a few years right after retirement age.

Figure 8. Male SAH and Labor Force Participation rate by age in 1977

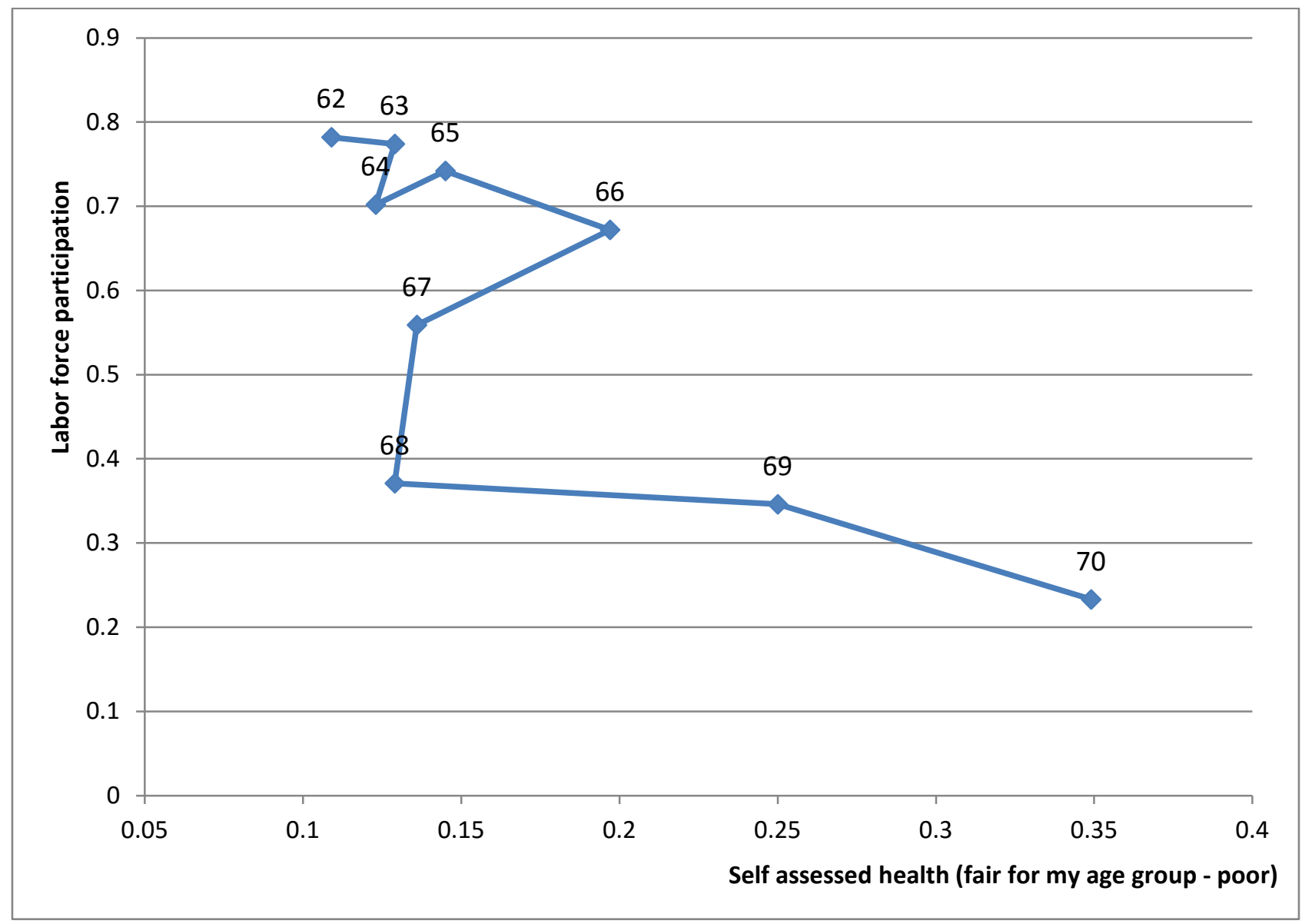

There is a 10-year gap until the next available SAH measure. Results from a survey conducted by the National Institute of Public Health in 1987 are shown in Figure 9. The horizontal axis measures the share of respondents at each age reporting health as fair-poor while the vertical axis measures labor force participation rates. For smoothing results are shown as 2 year averages. In 1987 PEW was fully phased in eligibility from ages 60 to 66 followed by OAP from age 67. The slope in Figure 9 is clearly negative with a major deterioration of SAH from age 55 to the early 60s, Notice the steep decline in labor force participation from the early 60s until eligibility to old age pension followed by a moderate improvement of self-assessed health in the late 60s. 
Figure 9. Male SAH and Labor Force Participation rates by age in 1986-87

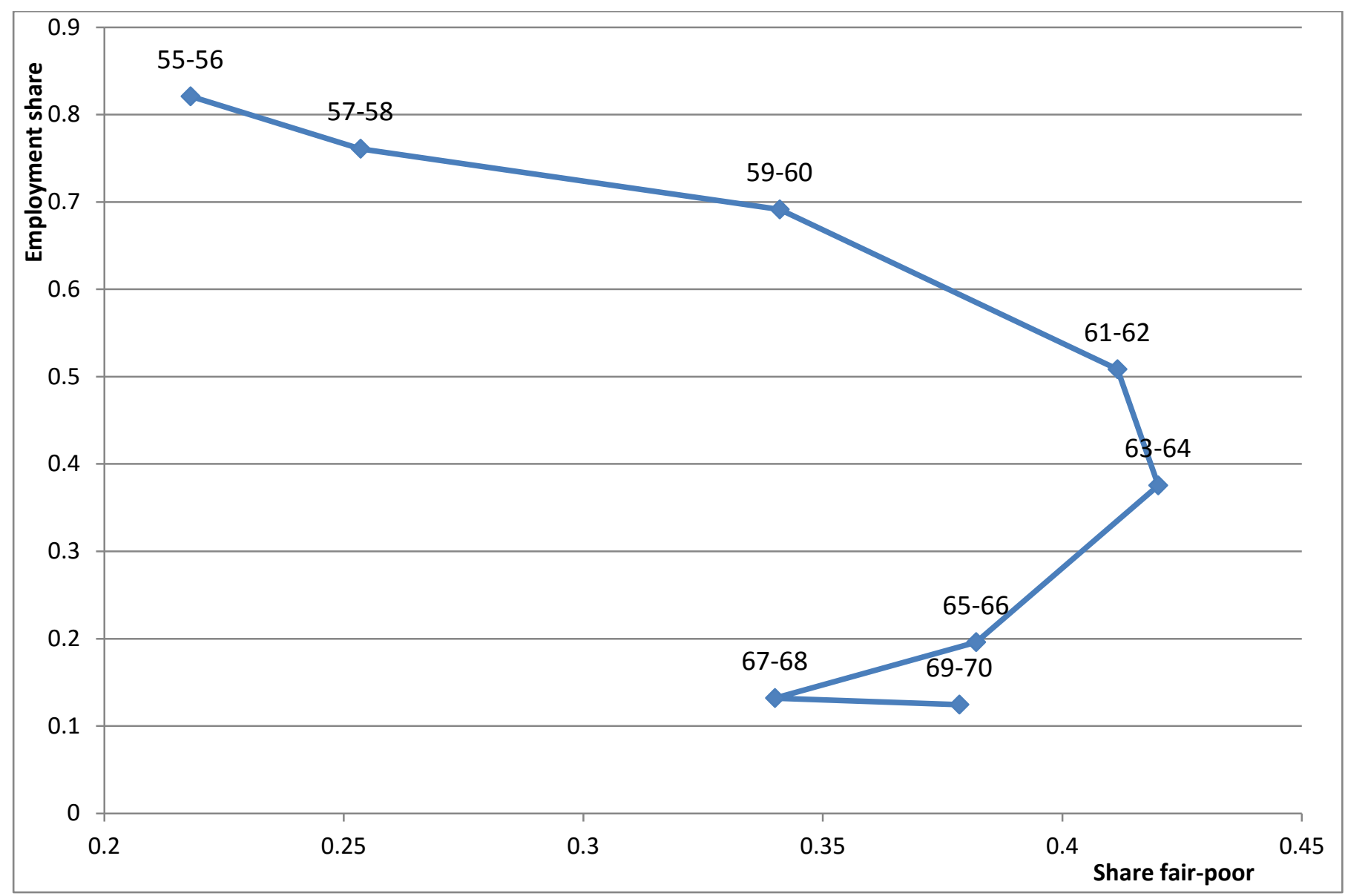

Data for Denmark from the ECHP collected in the years 1994-2001 over 8 waves makes it possible to construct a relationship between SAH and employment rates based on more observations by pooling over waves. The result is shown in Figure 10 for men ages 50-69. SAH deteriorates quite rapidly during the 50s while the 60s until age 67 are characterized by a steep drop in employment rates - more so in the PEW years than close to old age pension - at about the same level of SAH. After reaching pensionable age, SAH deteriorates again while employment rates remain around 10 per cent. 
Figure 10. Male SAH and Employment Rates by age 1994-2001.

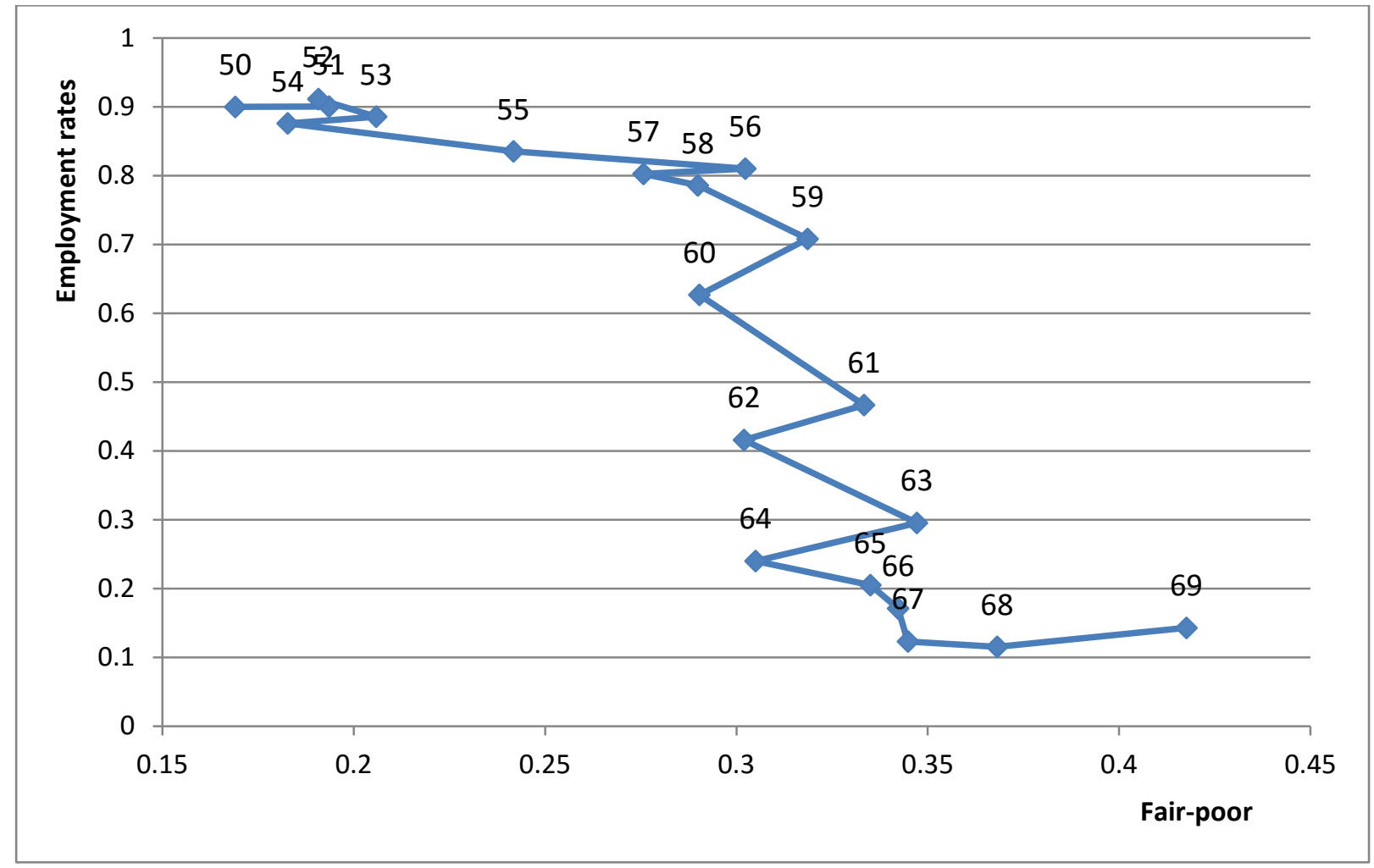

In Figure 11 we show the relationship between SAH and employment rates based on SHARE data from wave 4 collected in 2011. It appears that - after a transition from data points for single years to working with moving 3 year age averages - we still have a "noisy" relationship. However, like in Figure 10 we have a deterioration of health in the 50s followed by another phase of deterioration from the mid 60s. In between, employment rates drop significantly, first reflecting PEW and at higher age old age pension where the age of eligibility from 2004-6 has been 65 years. 
Figure 11. Male SAH and Labor Force Participation rates by age in 2011

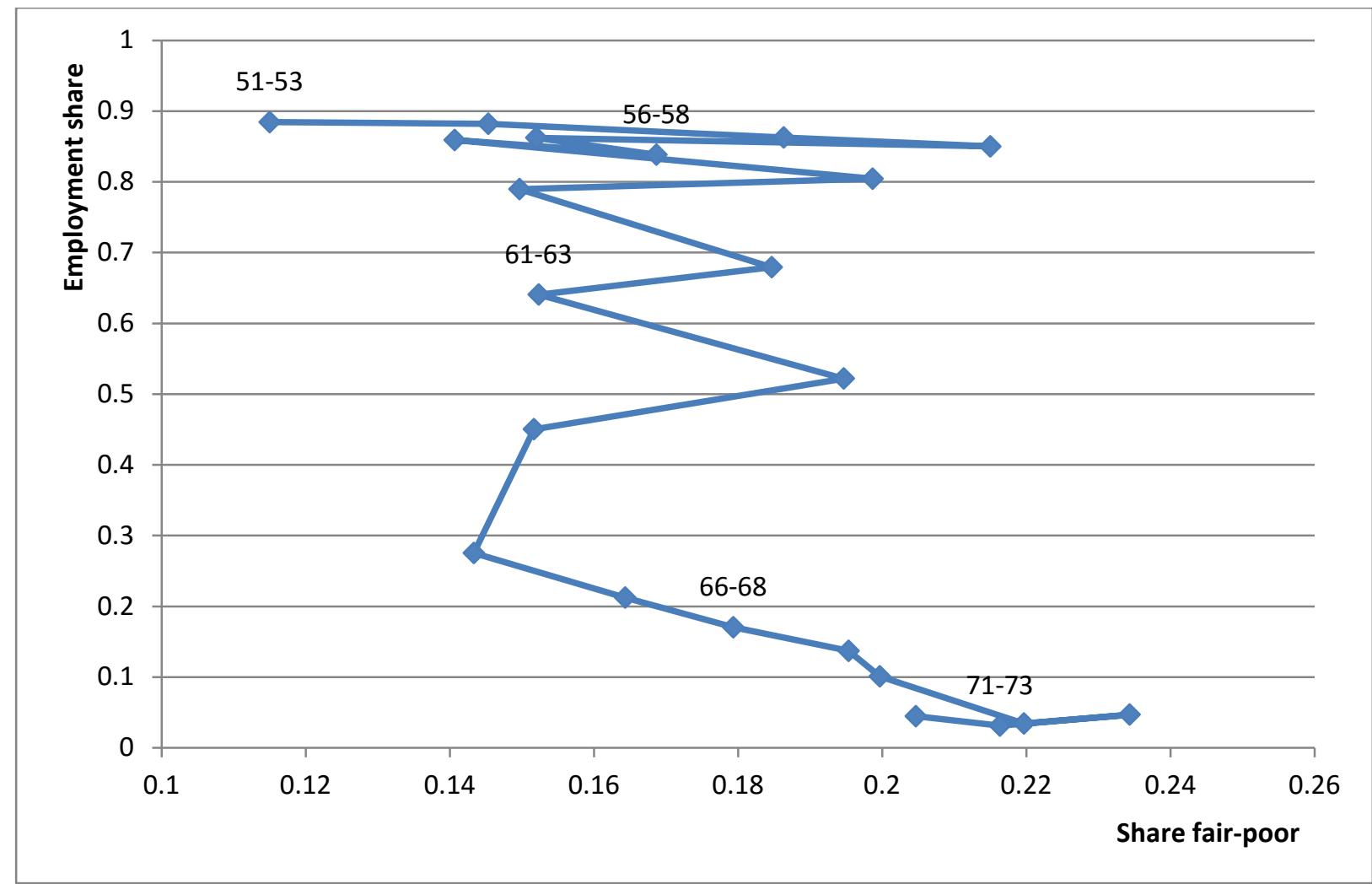

Once again using Danish data from the ECHP averaged over the 8 waves between 1994 and 2001, Figure 12 shows the relationship between SAH and employment, but now separately for the three education levels classified as ISCED 0-2, ISCED 3 and ISCED 5-7. Lines for different education levels are nearly completely separated. Employment rates are initially at the same level at 50 . The difference in employment rates has increased to 10 percentage points at age 55, increasing to a difference of 25 percentage points at age 65 .

In summary, the general pattern of reducing labour force participation rate and worsening SAH as men age is clear throughout. However, given the infrequency with which SAH has been surveyed in Denmark, and the lack of comparability of SAH between surveys it is not possible to speak about trends over time. Nevertheless, the relationship is steepest (greatest falls in participation for modest falls in SAH) during ages of eligibility to early pension benefits. There are striking SAH differentials by education, with the SAH deterioration from age 50 to 70 within schooling level (compulsory, high school and college) roughly equal to mean SAH differences between schooling 
levels. In the next section we analyse the SAH-employment and schooling relationship in more detail.

Figure 12. Male SAH and Employment Rates by age and schooling 1994-2001

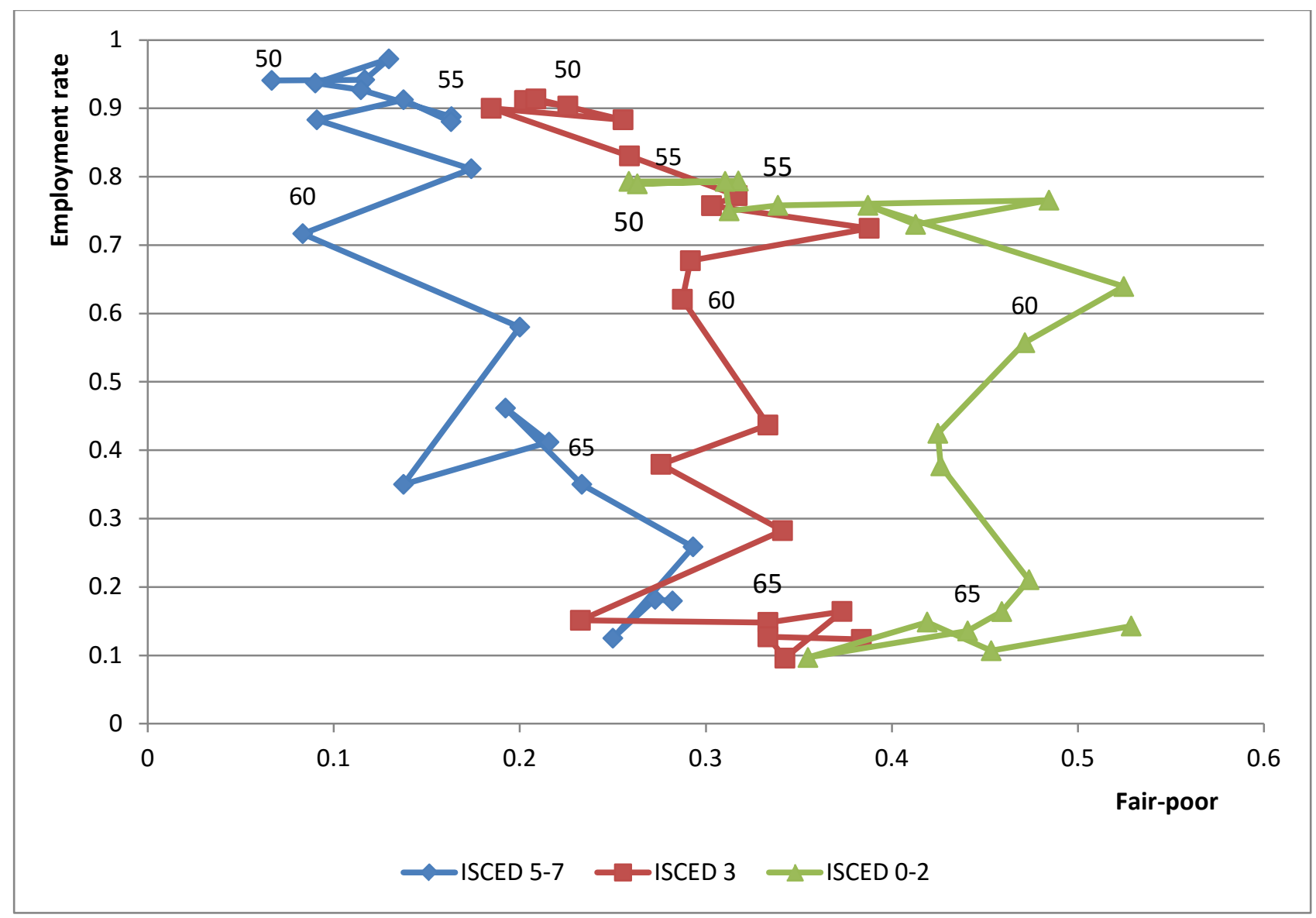

\section{Work Capacity estimates based on Self-Assessed Health}

In a second approach to estimating health capacity to work we ask how much would older cohorts work today, if they had the same relationship between SAH and employment as younger cohorts have today. This approach is inspired by Cutler and coauthors (2012) who use HRS data to estimate the relationship between SAH, retirement and Disability Insurance receipt for the near elderly and use estimates to simulate behavior of the elderly.

We use data from SHARE-Denmark which was collected in 2004, 2006, 2011 and 2013, that is waves 1, 2, 4 and 5. SHARE-life was conducted as wave 3 and contained retrospective questions about life histories, but not contemporaneous $\mathrm{SAH}$, so we cannot use this wave for the current 
analysis. SHARE is a longitudinal survey that collects data across nineteen European countries on individuals aged 50 or more and their spouses (Börsch-Supan et al., 2013). It has much in common with HRS, Japanese Study of Aging and Retirement (JSTAR) and English Longitudinal Study of Ageing (ELSA), making it an ideal dataset for our study which should be as comparable as possible with similar studies for other countries.

Table 3. Descriptive Statistics for SHARE-Denmark estimation and simulation sample

\begin{tabular}{|c|c|c|c|c|c|c|c|c|c|c|}
\hline & \multicolumn{4}{|c|}{ men } & & \multicolumn{5}{|c|}{ women } \\
\hline & $50-54$ & $\begin{array}{r}55- \\
59\end{array}$ & $\begin{array}{r}60- \\
64\end{array}$ & $\begin{array}{r}65- \\
69\end{array}$ & $\begin{array}{r}70- \\
74\end{array}$ & $\begin{array}{r}50- \\
54\end{array}$ & $\begin{array}{r}55- \\
59\end{array}$ & & $\begin{array}{r}65- \\
69\end{array}$ & $\begin{array}{r}70- \\
74\end{array}$ \\
\hline working & 0.862 & 0.826 & 0.551 & 0.159 & 0.037 & 0.827 & 0.758 & 0.402 & 0.078 & 0.019 \\
\hline high school & 0.456 & 0.450 & 0.448 & 0.471 & 0.457 & 0.272 & 0.317 & 0.337 & 0.368 & 0.347 \\
\hline college & 0.379 & 0.367 & 0.350 & 0.354 & 0.279 & 0.544 & 0.481 & 0.439 & 0.323 & 0.237 \\
\hline married & 0.700 & 0.684 & 0.728 & 0.699 & 0.659 & 0.728 & 0.670 & 0.666 & 0.624 & 0.582 \\
\hline SAH very good & 0.343 & 0.356 & 0.334 & 0.339 & 0.290 & 0.371 & 0.343 & 0.369 & 0.359 & 0.274 \\
\hline SAH good & 0.229 & 0.234 & 0.243 & 0.262 & 0.286 & 0.214 & 0.223 & 0.191 & 0.233 & 0.265 \\
\hline SAH fair & 0.106 & 0.125 & 0.133 & 0.159 & 0.185 & 0.107 & 0.154 & 0.188 & 0.141 & 0.216 \\
\hline SAH poor & 0.041 & 0.060 & 0.042 & 0.042 & 0.073 & 0.052 & 0.047 & 0.043 & 0.032 & 0.080 \\
\hline BMI undern & 0.003 & 0.000 & 0.001 & 0.005 & 0.004 & 0.021 & 0.016 & 0.025 & 0.023 & 0.034 \\
\hline BMI overv & 0.415 & 0.440 & 0.417 & 0.421 & 0.415 & 0.270 & 0.283 & 0.321 & 0.289 & 0.310 \\
\hline BMI o & 0.178 & 0.141 & 0.139 & 0.145 & 0.108 & 0.118 & 0.134 & 0.148 & 0.129 & 0.119 \\
\hline Limits any ADL & 0.037 & 0.043 & 0.053 & 0.066 & 0.086 & 0.049 & 0.046 & 0.057 & 0.050 & 0.084 \\
\hline Limit & .062 & 0.046 & 0.045 & 0.069 & 0.110 & 0.075 & 101 & 0.099 & 0.095 & 0.181 \\
\hline Limit & 0.104 & 0.110 & 0.152 & 0.164 & 0.138 & 0.096 & 0.128 & 0.121 & 0.160 & 0.188 \\
\hline physical 2+ & 0.099 & 0.116 & 0.117 & 0.130 & 0.213 & 0.161 & 0.196 & 0.257 & 0.213 & 0.338 \\
\hline doctor visit & 0.712 & 0.774 & 0.808 & 0.831 & 0.870 & 0.839 & 0.830 & 0.842 & 0.887 & 0.871 \\
\hline hospital stay & 0.064 & 0.097 & 0.113 & 0.122 & 0.167 & 0.082 & 0.096 & 0.108 & 0.099 & 0.134 \\
\hline nursing home sta & 0.000 & 0.000 & 0.006 & 0.000 & 0.004 & 0.000 & 0.000 & 0.003 & 0.003 & 0.002 \\
\hline back problems & 0.442 & 0.503 & 0.432 & 0.444 & 0.433 & 0.487 & 0.523 & 0.504 & 0.459 & 0.498 \\
\hline arthritis & 0.197 & 0.264 & 0.312 & 0.310 & 0.437 & 0.211 & 0.214 & 0.309 & 0.386 & 0.431 \\
\hline diabetes & 0.135 & 0.168 & 0.215 & 0.204 & 0.240 & 0.199 & 0.268 & 0.333 & 0.346 & 0.358 \\
\hline heart disease & 0.058 & 0.043 & 0.083 & 0.087 & 0.138 & 0.033 & 0.046 & 0.056 & 0.068 & 0.080 \\
\hline lung disease & 0.036 & 0.056 & 0.069 & 0.076 & 0.099 & 0.050 & 0.059 & 0.073 & 0.081 & 0.093 \\
\hline stroke & 0.033 & 0.033 & 0.032 & 0.043 & 0.084 & 0.021 & 0.023 & 0.020 & 0.023 & 0.039 \\
\hline hypertension & 0.011 & 0.021 & 0.031 & 0.050 & 0.044 & 0.050 & 0.044 & 0.055 & 0.060 & 0.069 \\
\hline cancer & 0.000 & 0.001 & 0.000 & 0.003 & 0.011 & 0.002 & 0.000 & 0.001 & 0.002 & 0.009 \\
\hline \# observations & 747 & 766 & 683 & 622 & 455 & 878 & 833 & 766 & 619 & 464 \\
\hline
\end{tabular}


Descriptive statistics for SHARE-Denmark are presented in table 3 by age group and gender. Our estimations and simulations will be conducted separately by gender and these age groupings. In total we have 3273 observations of men and 3650 observations of women. Proportion working is always higher for men than for women, is high and fairly stable before age 60 and then falls through age 70, most of the reduction taking place in the late 60's for men, but evenly throughout the 60s for women. Younger age groups have more schooling, especially at the college margin, and markedly so for women. SAH worsens with age, but levels and profiles are quite similar by gender. Men are much more likely to be overweight than women and there is a slight age gradient in obesity for men with younger men being more obese than older. Women have more limitations than men both physically and with regard to activities of daily living. Doctor visits are common for both men and women, though somewhat less for men in their 50's. Men are more likely to have had a hospital stay than women. Nursing home stays are very uncommon. Of the eight specific health conditions considered, back problems are the most common for all ages. Arthritis doubles from the early 50's to early 70's. Diabetes and hypertension are more common in women, and heart disease and stroke are more common in men.

In order to estimate the relationship between SAH and employment we need to characterize health in a way that allows for comparison with other countries. We calculate a single health index following Poterba and coauthors (2013), who create an index that is a reasonable predictor of mortality in HRS data. Using the health variables described in table 3, SAH, body mass index, types of limitations, care usage and a set of specific health conditions, we calculate the first principal component for both genders and all age groups pooled. This principal component is used to predict a single health index and we normalize this index to percentiles, where by convention a higher percentile indicates better health. For example (wo)men aged 50-54 have mean percentile 58 (54), (wo)men 70-74 have mean percentile 44 (39). 
Table 4. OLS regression estimates explaining employment ages 50-54

\begin{tabular}{lrlrl}
\hline & women & \multicolumn{3}{c}{ men } \\
\hline PVW health index & 0.0046 & 0.0004 & 0.0038 & 0.0004 \\
high school & 0.1001 & 0.0356 & 0.0631 & 0.0350 \\
college & 0.1826 & 0.0325 & 0.0884 & 0.0366 \\
married & 0.0629 & 0.0268 & 0.0522 & 0.0267 \\
2006 & 0.0049 & 0.0351 & 0.0734 & 0.0335 \\
2011 & 0.0215 & 0.0360 & 0.0628 & 0.0346 \\
2013 & 0.0215 & 0.0360 & 0.0628 & 0.0346 \\
intercept & 0.8563 & 0.0475 & 0.8724 & 0.0458 \\
\hline \# observations / R-sq & 878 & 0.1861 & 747 & 0.1337 \\
\hline
\end{tabular}

OLS regression estimates for the dependent variable working are presented in table 4. The sample is aged 50-54 and regressions are run separately for men and women. Better health is strongly and positively associated with employment. A move of 10 percentiles up the health distribution is associated with a 4.6 percentage point higher employment probability for women and 3.7 percentage point higher employment probability for men. High school and especially college is associated with higher employment probability. Married individuals are more likely to be working. Goodness-of-fit is somewhat better for women than for men.

Using the estimates from table 4 for the youngest of our age groups, we simulate work capacity by predicting on the basis of health and demographic characteristics for older age groups. In doing this we are assuming that the health-employment relationship is constant between age groups, so that we can meaningfully combine coefficients estimated on the younger group together with observed characteristics of the older groups for simulation. One threat to the stability of this relationship might be differences in skills, occupations and industry affiliation by age group. Jobs differ in their health demands and we need to assume the health-employment relationship is fixed across age groups for whom different types of jobs might be relevant. Furthermore, while our health index appears quite comprehensive, there may be health conditions we are unable to measure but which are negatively correlated with ability to work. Such omitted health factors would bias our work capacity estimates upward - we would be overstating the amount of unused work capacity. 
Table 5. Simulations of work capacity by age

\begin{tabular}{lrrrr}
$\begin{array}{l}\text { age } \\
\text { group }\end{array}$ & \# obs. & $\begin{array}{l}\text { actual } \\
\text { working }\end{array}$ & $\begin{array}{l}\text { predicted } \\
\text { capacity }\end{array}$ & $\begin{array}{l}\text { additional } \\
\text { capacity }\end{array}$ \\
\hline men & & & & \\
$55-59$ & 766 & $82.6 \%$ & $85.4 \%$ & $2.4 \%$ \\
$60-64$ & 683 & $55.1 \%$ & $84.7 \%$ & $29.2 \%$ \\
$65-69$ & 622 & $15.9 \%$ & $83.7 \%$ & $67.5 \%$ \\
$70-74$ & 455 & $3.7 \%$ & $80.2 \%$ & $76.2 \%$ \\
women & & & & \\
$55-59$ & 833 & $75.8 \%$ & $79.9 \%$ & $4.3 \%$ \\
$60-64$ & 766 & $40.2 \%$ & $77.9 \%$ & $37.9 \%$ \\
$65-69$ & 619 & $7.8 \%$ & $75.8 \%$ & $68.3 \%$ \\
$70-74$ & 464 & $1.9 \%$ & $70.2 \%$ & $68.1 \%$ \\
\hline
\end{tabular}

Results from the simulation exercise are presented in table 5 by age group and gender. Predicted work capacity changes only slightly with age, falling by 5 percent for men and 10 percent for women from the late 50's through till the early 70's. In order to simulate unused work capacity we calculate the difference between predicted work capacity and observed employment. When combined with observed employment levels which are rapidly declining with age, we simulate little unused work capacity in the late 50's, large unused capacity in the early 60's and very large unused capacity from the late 60's. Women's unused work capacity exceeds men's until the early 60's, whereas men have more unused capacity from their 70's. Figures 13a and 13b graphically present the simulation exercise from table 7. 
Figure 13a.

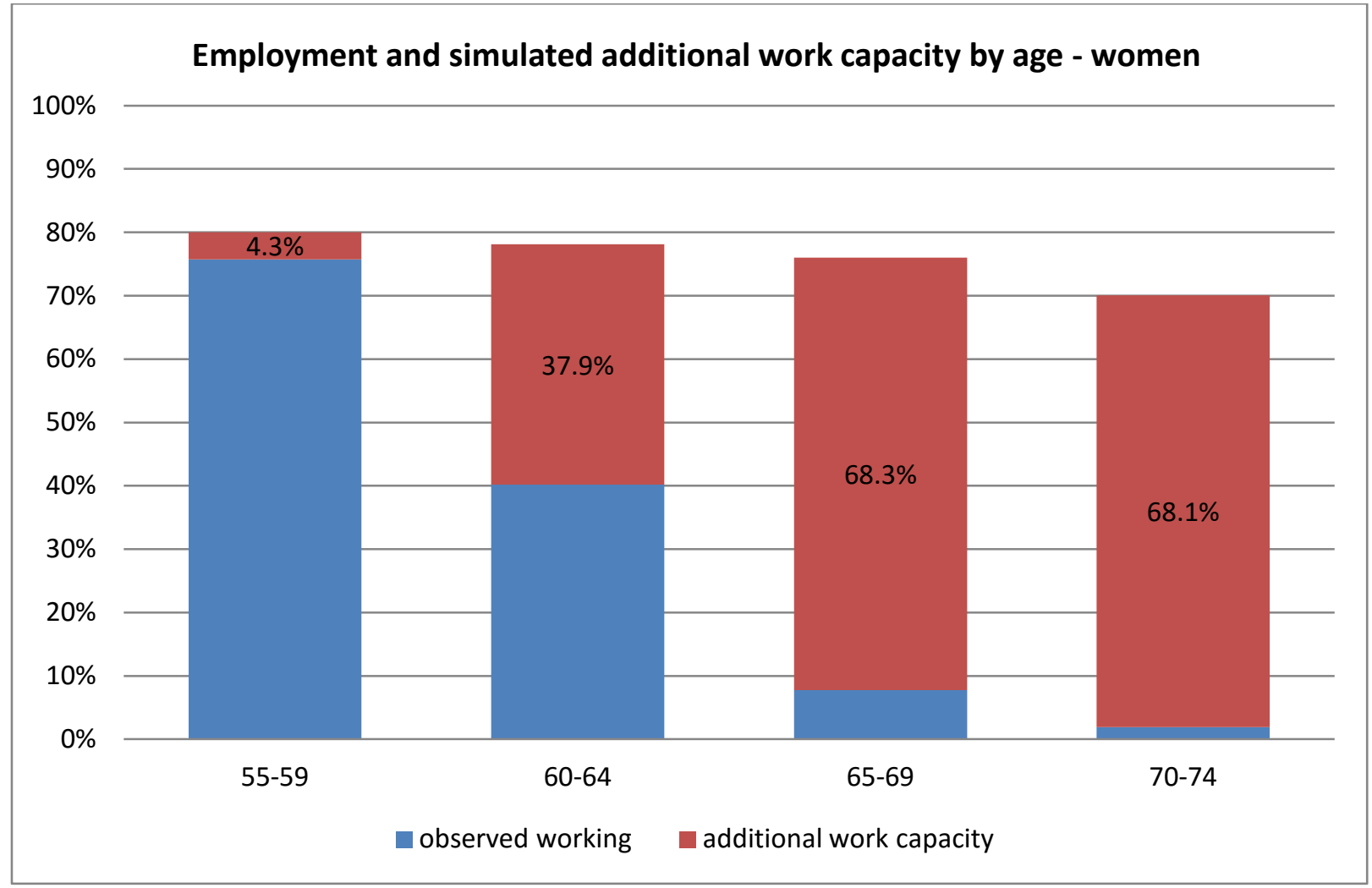

Figure 13b.

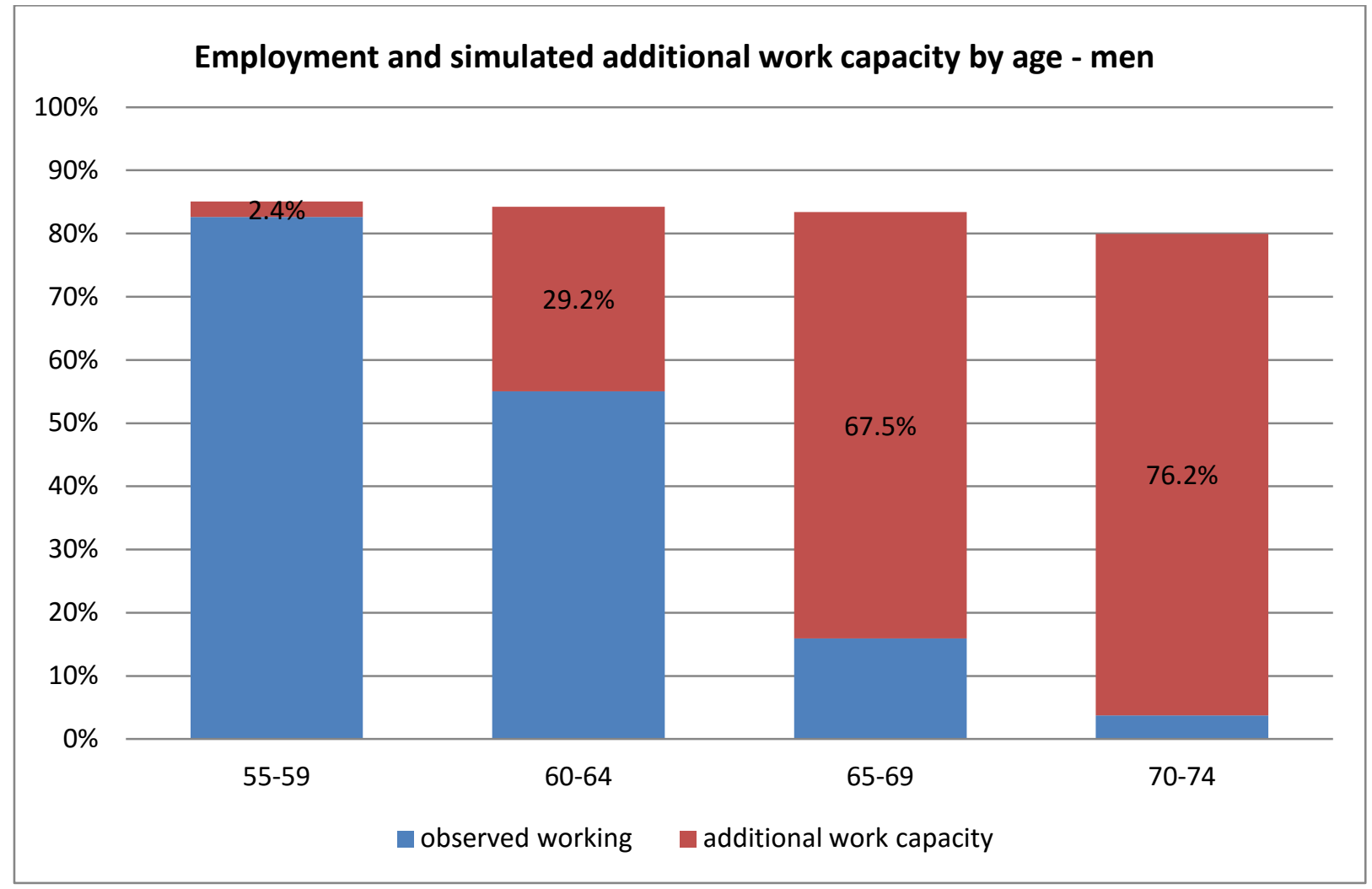


In table 6 we extend our simulation exercise on the basis of the same set of estimates from table 4, but now additionally splitting the simulation by level of schooling. Once again, similar information to that contained in table 6 is also presented visually in figures 14a and 14b. Employment differentials by schooling exceed differences in simulated work capacity across the age range, and especially so for women. Despite the large differences in work capacity by schooling, simulated unused work capacity is quite similar for the late 50's and early 60's. It is for the late 60's where schooling differences in unused work capacity are most obvious, increasing by 12 percent from primary to high school and 5 percent from high school to college for women, whereas it is increasing by 10 percent from primary to high school but decreasing by 16 percent from high school to college for men. Men in their late 60's with a college degree are much more likely to be employed than men of the same age with a high school diploma, whereas health for the two groups is quite similar, leading to a similar level of simulated work capacity.

Table 6. Simulations of work capacity by age group and schooling

\begin{tabular}{lrrrrrrrr} 
schooling & \# obs. & $\begin{array}{r}\text { actual } \\
\text { working }\end{array}$ & $\begin{array}{r}\text { predicted } \\
\text { capacity }\end{array}$ & $\begin{array}{r}\text { additional } \\
\text { capacity }\end{array}$ & \# obs. & $\begin{array}{r}\text { actual } \\
\text { working }\end{array}$ & $\begin{array}{r}\text { predicted } \\
\text { capacity }\end{array}$ & $\begin{array}{r}\text { additional } \\
\text { capacity }\end{array}$ \\
\hline $\begin{array}{l}\text { age 55-59 } \\
\text { primary }\end{array}$ & men & & & & women & & & \\
high school & 132 & $66.4 \%$ & $73.3 \%$ & $6.9 \%$ & 167 & $53.0 \%$ & $61.9 \%$ & $8.9 \%$ \\
college & 348 & $83.5 \%$ & $85.6 \%$ & $2.1 \%$ & 262 & $73.9 \%$ & $77.0 \%$ & $3.1 \%$ \\
age 60-64 & 286 & $89.7 \%$ & $90.3 \%$ & $0.6 \%$ & 404 & $86.5 \%$ & $89.6 \%$ & $3.0 \%$ \\
primary & 128 & $42.0 \%$ & $74.1 \%$ & $32.1 \%$ & 187 & $25.0 \%$ & $63.0 \%$ & $38.0 \%$ \\
high school & 312 & $55.2 \%$ & $84.4 \%$ & $29.2 \%$ & 251 & $30.2 \%$ & $73.8 \%$ & $43.6 \%$ \\
college & 243 & $62.3 \%$ & $89.8 \%$ & $27.5 \%$ & 328 & $55.7 \%$ & $89.1 \%$ & $33.5 \%$ \\
age 65-69 & & & & & & & & \\
primary & 116 & $9.2 \%$ & $74.5 \%$ & $65.3 \%$ & 192 & $4.2 \%$ & $62.1 \%$ & $57.9 \%$ \\
high school & 291 & $9.2 \%$ & $84.3 \%$ & $75.1 \%$ & 227 & $6.6 \%$ & $77.2 \%$ & $70.6 \%$ \\
college & 215 & $28.2 \%$ & $86.6 \%$ & $58.4 \%$ & 200 & $12.5 \%$ & $88.0 \%$ & $75.5 \%$ \\
age70-74 & & & & & & & & \\
primary & 113 & $0.0 \%$ & $73.4 \%$ & $73.4 \%$ & 187 & $1.6 \%$ & $58.9 \%$ & $57.3 \%$ \\
high school & 217 & $4.3 \%$ & $79.4 \%$ & $75.1 \%$ & 165 & $1.9 \%$ & $73.5 \%$ & $71.6 \%$ \\
college & 125 & $6.3 \%$ & $87.1 \%$ & $80.8 \%$ & 112 & $2.7 \%$ & $84.6 \%$ & $81.8 \%$ \\
\hline
\end{tabular}


Figure 14a.

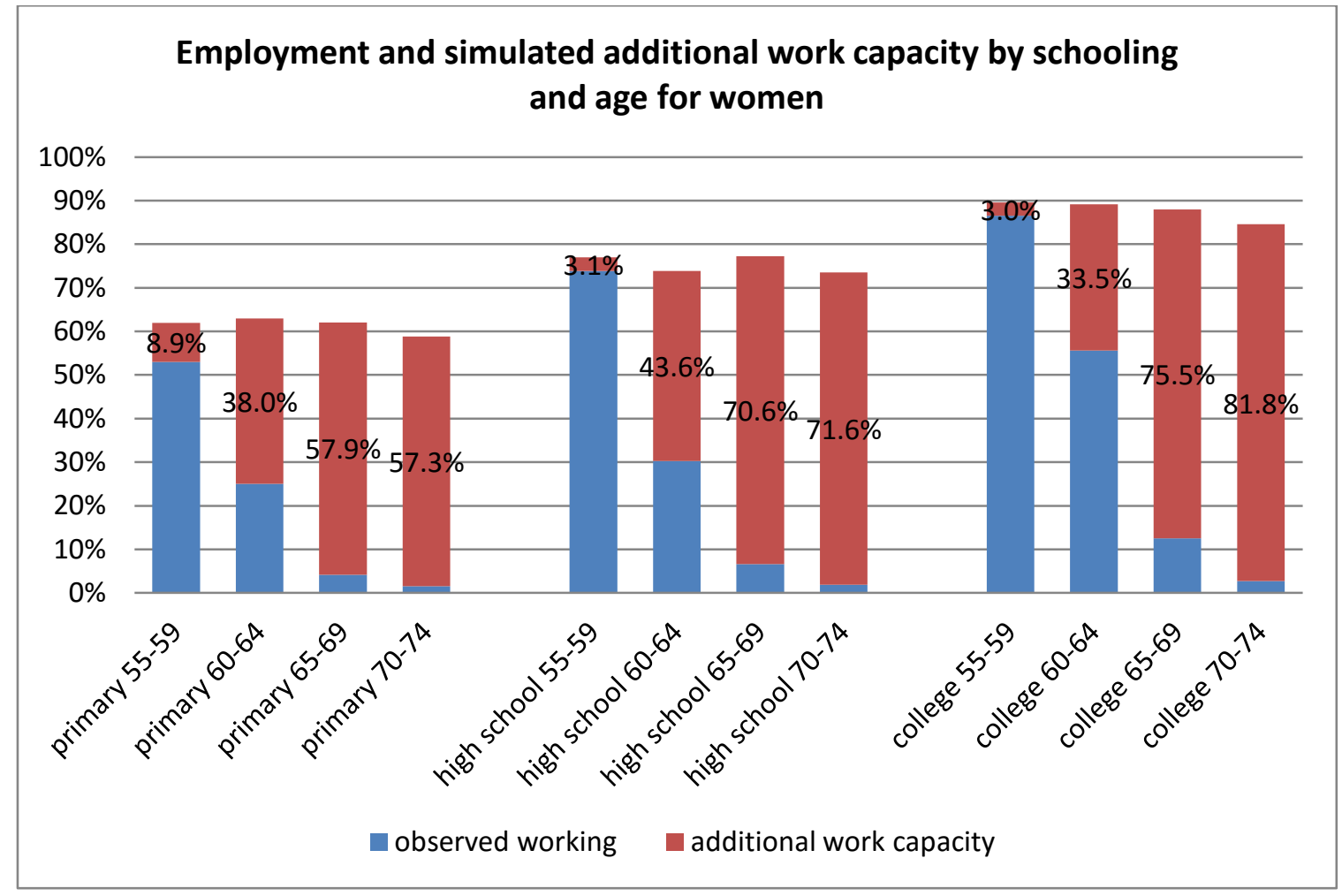

Figure 14b.

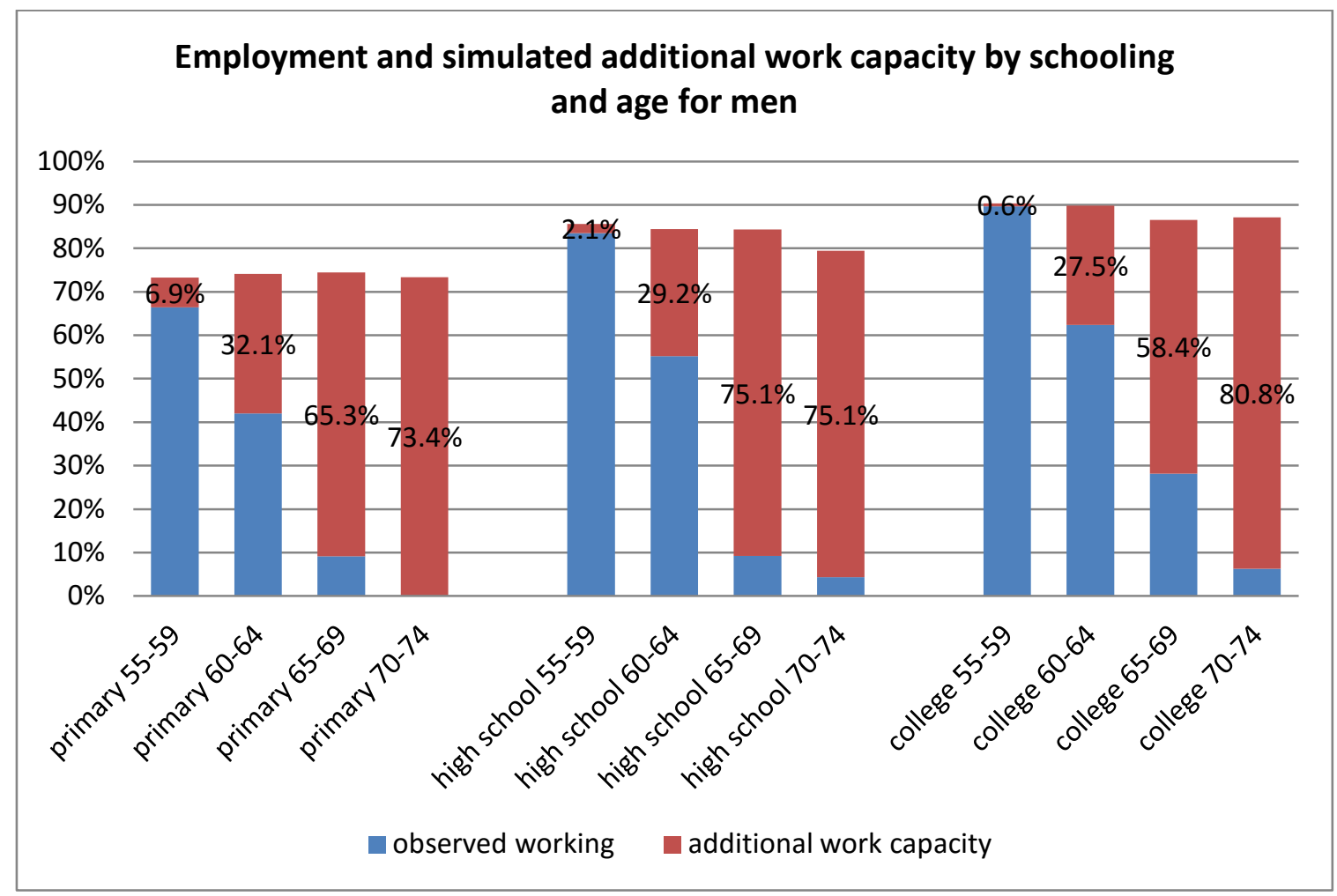


A convenient summary measure of unused work capacity that can be computed for this approach and for the previous approach is the total number of simulated years of unused work capacity over the age range 55-69. In section 3, Figure 7 presented implied years of unused capacity for different baselines. Our preferred baseline is 1977, which pre-dates the announcement of early pension benefits through the PEW program in 1978. This gives an unused work capacity for men of 4.6 years, which is consistent between methods. In table 7 we present simulated years of unused work capacity for our SAH based approach. For men this is quite close at 5.0 additional years. Women have 6 more months unused work capacity than men. By level of schooling, women with primary or high school have 3-4 months more unused work capacity than men, but at the college level women have a year longer unused work capacity than men. Men and women with high school degrees have 3-5 months more unused work capacity than those with different schooling.

Table 7. Simulated additional years of work capacity based on SAH ages 55-69

\begin{tabular}{lrrrr} 
schooling & $\begin{array}{r}\text { men } \\
\text { actual } \\
\text { working }\end{array}$ & $\begin{array}{r}\text { wdditional } \\
\text { capacity }\end{array}$ & $\begin{array}{r}\text { women } \\
\text { actual } \\
\text { working }\end{array}$ & $\begin{array}{r}\text { additional } \\
\text { capacity }\end{array}$ \\
\hline primary & 6.10 & 4.94 & 4.15 & 5.30 \\
high school & 7.34 & 5.35 & 5.60 & 5.85 \\
college & 8.68 & 4.63 & 7.61 & 5.60 \\
\hline all & 7.60 & 5.03 & 6.16 & 5.55 \\
\hline
\end{tabular}

\section{Conclusion}

Already mandated changes to future pension benefits will reduce incentives to retire early with the aim of extending the length of working lives. The implicit assumption is that older individuals actually have the health capacity to work longer. We have tested this assumption for Denmark using two methods. First, following Milligan and Wise (2012), we ask how much would older people work today, given current mortality rates, if they were to work as much as people did at a similar mortality rate in the past. Next, following Cutler and coauthors (2012), we ask how much would older cohorts work given their SAH, if they were to work as much as younger cohorts today do with similar SAH. Both are ways of estimating health-employment relationships that we then use for 
predicting how much work capacity there would be for older cohorts in similar health today if those estimated relationships held for today's older cohorts.

With both methods we find substantial unused work capacity. For men we are able to compare simulations between methods and findings are very similar when we consider a 1977 baseline for the mortality-employment relationship, before introduction of an important early pension benefit program. We simulate 4.6-5.0 additional years of health capacity to work for men between ages 55 and 69. This compares to baseline male employment of 7.6 years during 2004-13. For women we simulate 5.5 additional years of work capacity between ages 55 and 69, compared to baseline employment of 6.2 years. There are differences in additional work capacity by level of schooling. Those with a high school degree have the most unused work capacity. Women have more unused work capacity than men across the schooling distribution, especially at the college level where the difference is one year.

There are several caveats that need to be applied to our simulations. Most importantly our unused capacity numbers have no implications for how much older individuals should work. It is beyond the scope of our study to discuss whether longer working lives are desirable for society. Health has improved for the older population, whether measured by reduced mortality or better SAH, and this suggests that some additional work capacity is available. Both of the approaches we have followed assume that all health gains can be translated into longer working lives, but there are significant real world constraints on this, such as labor demand, workplace discrimination and accommodation, and household and family factors. Our additional work capacity simulations are quite large and these caveats should moderate those somewhat. Nevertheless, our aim was to ask whether Danes have the health capacity to extend working lives by three years over the next fifteen, as currently announced policies assume. Our findings suggest that this additional health capacity to work does indeed exist. 


\section{References}

Bingley P, Datta Gupta N, Pedersen PJ. The impact of incentives on retirement in Denmark, in Gruber J, Wise D (eds.) Social Security Programs and Retirement Around the World: Microestimation. 2004; University of Chicago Press.

Bingley P, Datta Gupta N, Pedersen PJ. Disability Programs, Health and Retirement in Denmark since 1960, in Wise D (ed.) Social Security Programs and Retirement Around the World: Historical Trends in Mortality and Health, Employment and Disability Insurance Participation and Reforms. 2012; University of Chicago Press.

Bingley P, Datta Gupta N, Pedersen PJ. Health, Disability Insurance and Retirement in Denmark, in Wise D (ed.) Social Security Programs and Retirement Around the World: Disability Insurance Programs and Retirement. 2015; University of Chicago Press.

Brønnum-Hansen, H., O. Andersen, M. Kjøller and N.K. Rasmussen. 2004. Social gradient in life expectancy and health expectancy in Denmark. Soz.-Präventivmed. 49: 36-41.

Brønnum-Hansen, H. 2005. Health Monitoring. Health expectancy in Denmark, 1987-2000. European Journal of Public Health, Vol. 15, No. 1, 20-25.

Christensen, K., G. Doblhammer, R. Rau and J.W. Vaupel. 2009. Ageing populations: the challenges ahead. Lancet, vol. 374, No. 9696, 1196-1208.

Cutler, David M., Ellen Meara, and Seth Richards-Shubik (2012). "Health and Work Capacity of Older Adults: Estimates and Implications for Social Security Policy, mimeo.

Ekholm, O., M. Kjøller, M. Davidsen, U. Hesse, L. Eriksen, A.I. Christensen and M. Grønbæk. 2006. Sundhed og sygelighed i Danmark \& udviklingen siden 1987. (Health and morbidity in Denmark \& the development since 1987). National Institute of Public Health. Copenhagen.

Larsen, M. and P.J. Pedersen. 2013. To work, to retire - or both? Labor market activity after 60. IZA Journal of European Labor Studies. 2-21.

Larsen, M. and P.J. Pedersen. 2015. Labor force activity after 60: Recent trends in the Scandinavian Countries. Preliminary.

Mathers, C.D., R. Sadana, J.A. Salomon, C.J.L. Murray and A.D. Lopez. 2001. Healthy life expectancy in 191 countries, 1999. Lancet, vol. 357, No. 9269, 1685-1691.

Milligan, K.S. and D.A. Wise. 2012. Health and Work at Older Ages: Using Mortality to Assess the Capacity to Work Across Countries. NBER Working Paper 18229.

OECD (2011), "Pensionable Age and Life Expectancy, 1950-2050", in Pensions at a Glance 2011: Retirement-income Systems in OECD and G20 Countries, OECD Publishing. 
Poterba, James, Steven Venti, and David A. Wise (2013), "Health, Education, and the Postretirement Evolution of Household Assets" Journal of Human Capital, Vol. 7, No. 4, pp. 297-339.

Social- og Integrationsministeriet (2013a): Bekendtgørelse af lov om social pension. www.retsinformation.dk/Forms/R0710.aspx?id=145406.

Sullivan, D.F. 1971. A single index of mortality and morbidity. Health Services and Mental Health Administration (HSMHA). Health Report, 86: 347-354.

Whitehouse, E.R. (2007), "Life-expectancy risk and pensions: who bears the burden?" Social, Employment and Migration Working Paper no. 60, OECD, Paris.

Wise, David (2015) Social Security Programs and Retirement Around the World: Disability Insurance Programs and Retirement; University of Chicago Press. 


\section{Notes to tables and figures}

Figure 1. Sources: Population census 1960, 1965 and 1970; annual labor force surveys 1973-1975; annual statistics based upon a 10 percent administrative sample 1976-79; 1980-2013 administrative data on the full population.

Figure 2. Sources: Population census 1960, 1965 and 1970; annual labor force surveys 1973-1975; annual statistics based upon a 10 percent administrative sample 1976-79; 1980-2013 administrative data on the full population.

Figure 3. Sources: Mortality rates from Statistics Denmark. SAH from two surveys by the National Institute of Public Health of 1100 men aged 50-75 with response categories excellent, very good, good, fair or poor.

Figure 4. Sources: Mortality rates from Statistics Denmark. Employment rates from Statistics Denmark based on annual information from administrative registers using a 10 percent sample in 1979 and the full population in 2010.

Figure 5. Sources: Mortality rates from Statistics Denmark. Employment rates from Statistics Denmark based on annual information from administrative registers for the population.

Figure 6. Sources: Mortality rates from Statistics Denmark. Employment rates from Statistics Denmark based on annual information from administrative registers using a 10 percent sample in 1976-79 and the full population in 1980, 1991-95 and 2006-10.

Figure 7. Own calculations based on mortality rates from Statistics Denmark and employment rates from Statistics Denmark based on annual information from administrative registers using a 10 percent sample 1977-79 and the full population 1980-2010.

Figure 8. Sources: Labour force participation rates from Statistics Denmark based upon a 10 percent administrative sample. SAH from a survey of 600 men conducted by SFI (Olsen, 1977). Our SAH means are based on micro data from this survey retrieved from Danish Data Archive Study \#00232. SAH response categories are good, good for my age, fair, fair for my age, poor.

Figure 9. Sources: Employment rates from Statistics Denmark based upon administrative data for the population. SAH from a survey of 1000 men conducted by the National Institute of Public Health. Our SAH means are based on micro data from this survey retrieved from Danish Data Archive Study \#01435. SAH response categories are excellent, very good, good, fair or poor.

Figure 10. Sources: Employment rates from Statistics Denmark based upon administrative data for the population. SAH from ECHP 1994-2001 (waves 1-8) containing 4000 Danish men aged 50-69. SAH response categories are very good, good, fair, bad, very bad.

Figure 11. Sources: Employment rates from Statistics Denmark based upon administrative data for the population. SAH from SHARE-Denmark 2011 (wave 4) containing 900 men age 51-73. SAH response categories are very good, good, fair, poor, very bad. 
Figure 12. Sources: Employment rates from Statistics Denmark based upon administrative data for the population. SAH from ECHP 1994-2001 (waves 1-8) containing 4000 Danish men aged 50-69. SAH response categories are very good, good, fair, bad, very bad. ISCED codes 0-2, 3 and 5-7 correspond to compulsory schooling, high school and college respectively.

Figure 13. Own calculations based on SHARE-Denmark waves 1, 2, 4 and 5. Simulations are based on estimates presented in table 4. This is an alternative presentation of selected material from table 5.

Figure 14. Own calculations based on SHARE-Denmark waves 1, 2, 4 and 5. Simulations are based on estimates from data which is pooled across education groups and presented in table 4 . This is an alternative presentation of selected material from table 6 .

Table 1. Own calculations based on mortality rates from Statistics Denmark and employment rates from Statistics Denmark based on annual information from administrative registers using a 10 percent sample in 1979 and the full population in 2010.

Table 2. Own calculations based on mortality rates from Statistics Denmark and employment rates from Statistics Denmark based on annual information from administrative registers for the population.

Table 3. Own calculations based on SHARE-Denmark waves 1, 2, 4 and 5. Omitted groups are those with compulsory schooling, very poor SAH, normal BMI, no limitations in Activities of Daily Living (ADL), no limitations in Instrumental Activities of Daily Living IADL, no limitations in physical activity, no doctor visits, no hospital stays, no nursing home stays, and none of the remaining health conditions.

Table 4. Own calculations based on SHARE-Denmark waves 1, 2, 4 and 5. PVW health index is calculated as first principal component from health conditions listed in table 3 (see Poterba and coauthors 2013). Reference category for education is compulsory schooling. 2004 is the reference year.

Table 5. Own calculations based on SHARE-Denmark waves 1, 2, 4 and 5. Simulations are based on estimates presented in table 4.

Table 6. Own calculations based on SHARE-Denmark waves 1, 2, 4 and 5. Simulations are based on estimates from data which is pooled across education groups and presented in table 4 .

Table 7. Own calculations based on SHARE-Denmark waves 1, 2, 4 and 5. Simulations are based on estimates from data which is pooled across education groups and presented in table 4 . 